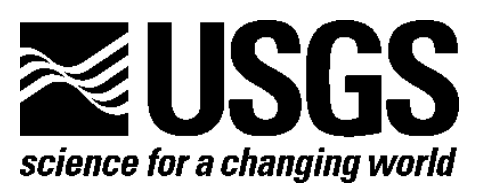

\title{
Regional Spectral Analysis of Moderate Earthquakes in Northeastern North America-Final Report to the Nuclear Regulatory Commission, Project V6240, Task 3
}

By John Boatwright

Open-File Report 2018-1073 


\section{U.S. Department of the Interior RYAN K. ZINKE, Secretary \\ U.S. Geological Survey James F. Reilly II, Director}

U.S. Geological Survey, Reston, Virginia: 2018

For more information on the USGS—-the Federal source for science about the Earth, its natural and living resources, natural hazards, and the environment-visit https://www.usgs.gov/ or call 1-888-ASK-USGS (1-888-275-8747).

For an overview of USGS information products, including maps, imagery, and publications, visit https://store.usgs.gov/.

Any use of trade, firm, or product names is for descriptive purposes only and does not imply endorsement by the U.S. Government.

Although this information product, for the most part, is in the public domain, it also may contain copyrighted materials as noted in the text. Permission to reproduce copyrighted items must be secured from the copyright owner.

Suggested citation:

Boatwright, J., 2018, Regional spectral analysis of moderate earthquakes in northeastern North America-Final report to the Nuclear Regulatory Commission, project V6240, task 3: U.S. Geological Survey Open-File Report 2018-1073, 39 p., https://doi.org/10.3133/ofr20181073.

ISSN 2331-1258 (online) 


\section{Preface}

This report was prepared as an account of work sponsored by an agency of the U.S. Government. Neither the U.S. Government nor any agency thereof, nor any of their employees, makes any warranty, expressed or implied, or assumes any legal liability or responsibility for any third party's use, or the results of such use, of any information, apparatus, product, or process disclosed in this report, or represents that its use by such third party would not infringe privately owned rights. The views expressed in this paper are not necessarily those of the U.S. Nuclear Regulatory Commission. 


\section{Contents}

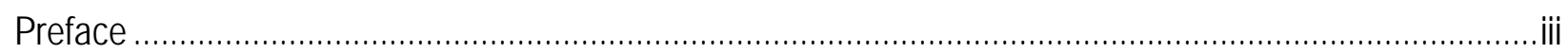

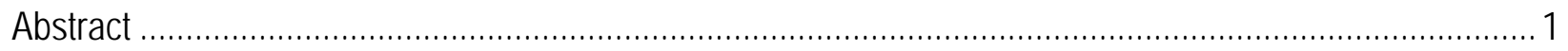

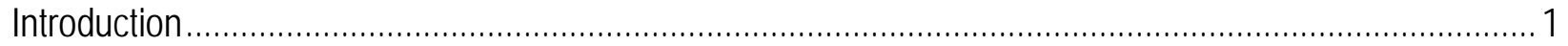

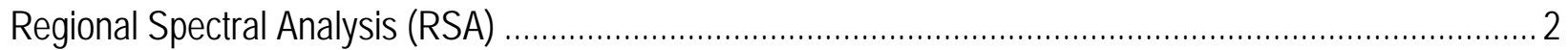

Comparing RSA Moments to Estimates from Moment Tensor Analyses ...............................................

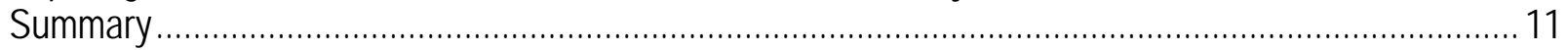

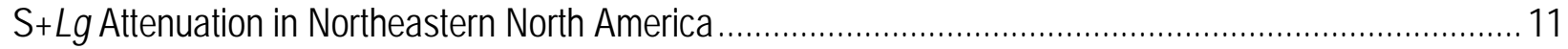

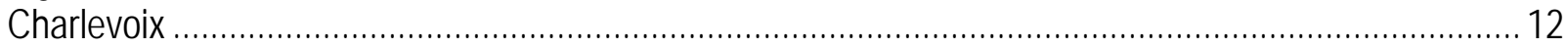

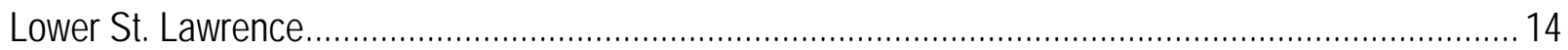

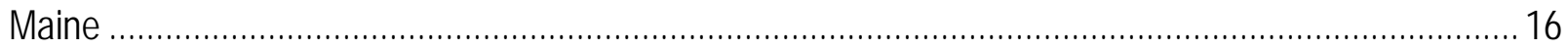

Northern New York

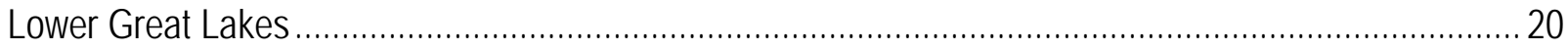

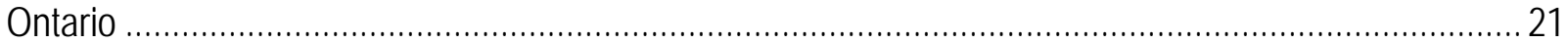

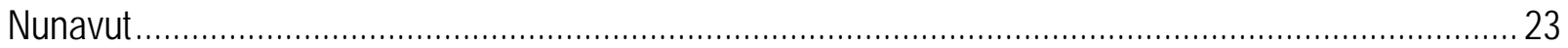

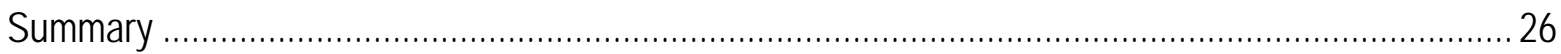

Earthquake Stress Drops in Northeastern North America...................................................................... 27

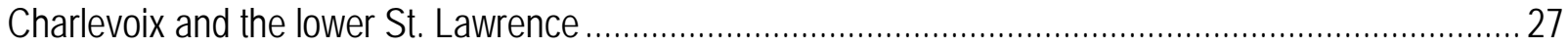

Ontario, western Quebec, New York State, and Nunavut.................................................................. 30

New England, Pennsylvania, Virginia, Ohio, and Michigan ............................................................... 34

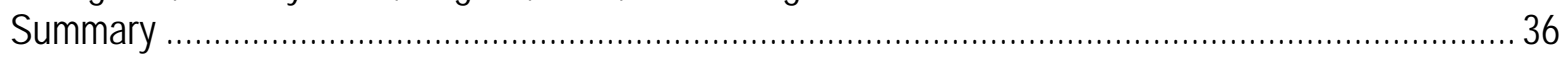

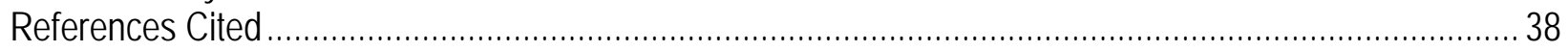

\section{Figures}

Figure 1. Graphs of S-wave velocity structures assumed for hard and firm-rock sites in northeastern North

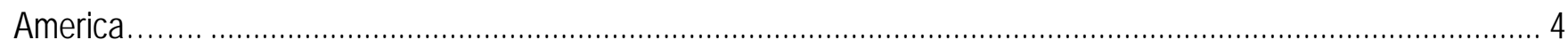

Figure 2. Graph displaying spectral analysis of the moment magnitude $\left(M_{\mathrm{w}}\right) 3.4$ aftershock of the $M_{\mathrm{w}} 4.9$

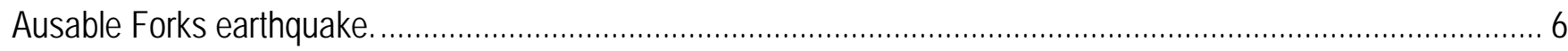

Figure 3. Graph showing moment magnitude $\left(M_{\mathrm{w}}\right)$ differences $(\mathrm{d} M \mathrm{w})$ plotted as a function of source depth..... 8

Figure 4. Graph showing moment magnitude $\left(M_{\mathrm{w}}\right)$ differences $(\mathrm{d} M \mathrm{w})$ plotted as a function of regional spectral

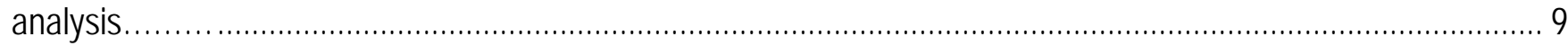

Figure 5. Graph of spectral analysis of the 1990 Mont Laurier earthquake.............................................. 10

Figure 6. Graph of moment magnitude $(M w)$ differences (dMw) between the Atkinson (2004) and regional spectral analysis estimates plotted as a function of regional spectral analysis 


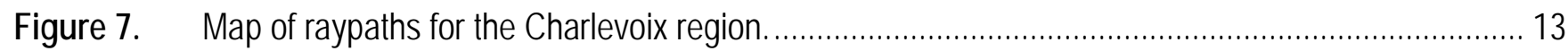

Figure 8. Graph of attenuation estimates from 10 earthquakes in Charlevoix and southeastern Quebec........14

Figure 9. Map of raypaths for lower St. Lawrence earthquakes.................................................................. 15

Figure 10. Graph of attenuation estimates from 7 earthquakes in the lower St. Lawrence area........................ 16

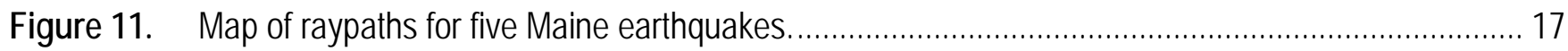

Figure 12. Graph of attenuation estimates from 5 earthquakes in Maine ……........................................... 18

Figure 13. Map of raypaths from 4 earthquakes in New York.................................................................. 19

Figure 14. Graph of attenuation estimates from 4 earthquakes in New York............................................... 19

Figure 15. Map of raypaths for five earthquakes in Ohio, Pennsylvania, and Lake Ontario................................ 20

Figure 16. Graph of attenuation estimates from 5 earthquakes in Ohio, Pennsylvania, and southern Ontario... 21

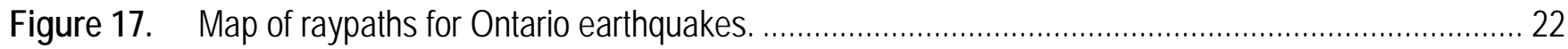

Figure 18. Graph of attenuation estimates for 10 earthquakes in Ontario and western Quebec........................ 23

Figure 19. Map of ray-paths for northern Hudson Bay earthquakes. .............................................................. 24

Figure 20. Graph of attenuation estimates for 5 events in Nunavut............................................................. 25

Figure 21. Graph of attenuation estimates from four earthquakes in Nunavut............................................... 26

Figure 22. Map of epicenters of earthquakes in Charlevoix, the Lower St. Lawrence, New Brunswick, and New

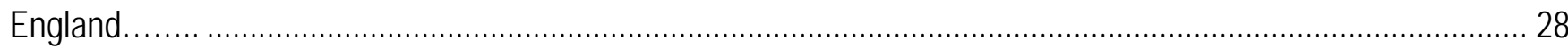

Figure 23. Graph of stress drop plotted against moment magnitude for Charlevoix, lower St. Lawrence, and New

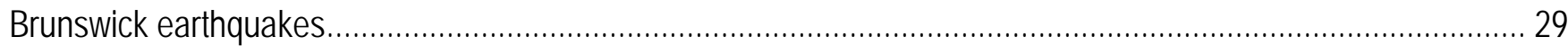

Figure 24. Graph of stress drop plotted against source depth for Charlevoix, lower St. Lawrence, and New

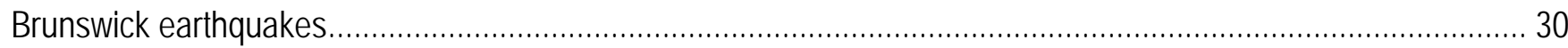

Figure 25. Map of epicenters of earthquakes in Ontario, western Quebec, and central and eastern United

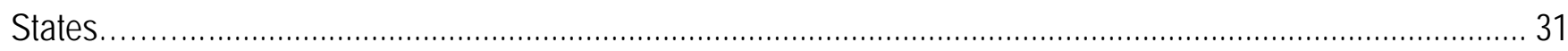

Figure 26. Map of epicenters of earthquakes in Nunavut and northern Quebec that were analyzed................... 32 
Figure 27. Graph of stress drop plotted against moment magnitude for the Ontario, western Quebec, New York, and Nunavut earthquakes.

Figure 28. Graph of stress drop plotted against source depth for Ontario, western Quebec, New York, and Nunavut earthquakes. 34

Figure 29. Graph of stress drop plotted against moment magnitude for New England, Pennsylvania, Virginia, Ohio, and Michigan earthquakes.

Figure 30. Graph of stress drop plotted against source depth for New England, Pennsylvania, Virginia, Ohio, and Michigan earthquakes.

\section{Tables}

Table 1. Moment magnitude $\left(M_{\mathrm{w}}\right)$ estimates from moment tensor and regional spectral analyses. ..................... 6

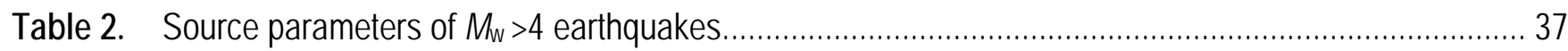




\section{Abbreviations}

$\begin{array}{ll}\text { CNSN } & \text { Canadian National Seismic Network } \\ \mathrm{g} & \text { gram } \\ \mathrm{g} / \mathrm{cm} 3 & \text { grams per cubic centimeter } \\ \mathrm{Hz} & \text { cycles per second } \\ \mathrm{km} & \text { kilometer } \\ \mathrm{km} / \mathrm{s} & \text { kilometers per second } \\ \text { LCSN } & \text { Lamont Community Seismic Network } \\ M_{w} & \text { moment magnitude [] } \\ \mathrm{NENA} & \text { northeastern North America } \\ \mathrm{NESN} & \text { New England Seismic Network } \\ \text { POLARIS } & \text { seismic network in Canada run by Polaris Seismic, Ltd. } \\ \text { RSA } & \text { regional spectral analysis } \\ \mathrm{S} & \text { second } \\ \text { USGS } & \text { U.S. Geological Survey } \\ \text { USNSN } & \text { United States National Seismic Network } \\ \text { WWSSN } & \text { World-Wide Standardized Seismograph Network }\end{array}$




\title{
Regional Spectral Analysis of Moderate Earthquakes in Northeastern North America-Final Report to the Nuclear Regulatory Commission, Project V6240, Task 3
}

\author{
By John Boatwright
}

\begin{abstract}
We analyze the Fourier spectra of $S+L g+$ surface wave groups from the horizontal and vertical components of broadband and accelerogram recordings of 120 small and moderate $\left(2<M_{\mathrm{w}}<6\right)$ earthquakes recorded by Canadian and American stations sited on rock at distances from 3 to 600 kilometers. There are seven $M_{\mathrm{w}} 4.0-4.5$, six $M_{\mathrm{w}} 4$.5-5.0, and three $M_{\mathrm{w}} \geq 5$ earthquakes in this event set. We test the regional spectral analysis by comparing the moment magnitudes with the moment magnitudes from the earthquake moment tensors determined by Bob Herrmann (St. Louis University) for 27 events, obtaining $\mathrm{d} M_{\mathrm{w}}=0.004 \pm 0.074$. We determine the $L g$ attenuation in seven regions within northeastern North America: Charlevoix, lower St. Lawrence, Maine, Northern New York, lower Great Lakes, Ontario, and Nunavut. These attenuation estimates yield an average attenuation $Q=(368 \pm 13) f^{(0.54 \pm 0.02)}$ for the Appalachian region, a stronger attenuation $Q=(317 \pm 16) f^{(0.54 \pm 0.03)}$ for the Appalachian lowlands, and a weaker attenuation $Q=(455 \pm 20) f^{(0.51 \pm 0.02)}$ for Ontario and western Quebec. For events in Nunavut and northernmost Quebec, we estimate a similar attenuation for $r<450 \mathrm{~km}$, but a weaker attenuation $Q=(773 \pm 70) f^{(0.27 \pm 0.06)}$ for $L g$ propagation for $450<r<1700$ kilometers. This farregional attenuation allows us to analyze recordings of the 1989 Ungava and Payne Bay earthquakes obtained in Ontario and southern Quebec. We use these regional attenuations to determine the corner frequencies, stress drops, and radiated energies of the 120 earthquakes.
\end{abstract}

\section{Introduction}

Boatwright and Seekins (2011) analyzed regional broadband and accelerograph recordings of four moderate (moment magnitude $\left[M_{\mathrm{w}}\right]$ 4.4-5.8) earthquakes in northeastern North America (NENA), including the $1988 M_{\mathrm{w}} 5.8$ Saguenay, Quebec, Canada earthquake (Somerville and others, 1990). In this report, we use Boatwright and Seekins’ regional spectral analysis (RSA) technique to analyze 116 earthquakes that have occurred in NENA since 1988. The resulting thirty-year catalog of moderate earthquakes contains thirteen $M_{\mathrm{w}} 4-5$ and three $M_{\mathrm{w}} \geq 5$ NENA earthquakes. Five events, the $1994 M_{\mathrm{w}} 4.6$ Reading, Penn., the $1997 M_{\mathrm{w}} 5.0$ Nunavit, Nunavut, Canada, the $2004 M_{\mathrm{w}} 4.2$ Southampton Island, Nunavut, Canada, the $2012 M_{\mathrm{w}} 4.1$ Waterboro, Maine, and the $2015 M_{\mathrm{w}} 4.4$ Galesburg, Mich. earthquakes, have not been spectrally analyzed by other authors.

The catalog of $M_{\mathrm{w}}<4$ earthquakes is not complete, but adequately represents the regional extent and range of hypocentral depths of NENA earthquakes. The regional spectral analysis must be modified for smaller events because the microseismic noise in NENA, driven by storms in the North Atlantic, can exceed the long-period spectral levels of these earthquakes at stations beyond 200 kilometers $(\mathrm{km})$. 
These modifications are straightforward: we reduce the limiting distance for the stations, and we measure the long-period level at frequencies above the frequency band of the microseismic noise.

The results of these new spectral analyses corroborate and extend the results of Boatwright and Seekins (2011). The attenuation of the crustal $L g$ phase that is estimated from the earthquakes in eastern Quebec and New England is slightly stronger but similar to the $Q=410 f^{0.5}$ attenuation obtained by Boatwright and Seekins (2011). Here $Q$ is the quality factor for the attenuation and $f$ is the frequency, in Hz. We associate this attenuation with the Appalachian Province. For earthquakes in western Quebec and Ontario, we estimate an average $L g$ attenuation of $Q=540 f^{0.46}$ and associate this attenuation with the Grenville Province. Both of these attenuation functions are similar to Atkinson and Boore's (2014) average for NENA, $Q=525 f^{0.45}$.

Given the average $L g$ attenuation determined by Atkinson and Boore (2014) for NENA, it is reasonable to ask if these spatial details of $L g$ attenuation in NENA are needed to predict strong ground motions for future large earthquakes. They are needed for two reasons.

1. Estimates of $\mathrm{Lg}$ attenuation have a direct effect on the prediction of near-source ground motions. The stronger the attenuation, the larger the inferred stress drops and the larger the predicted nearsource ground motion.

2. The predictions also depend on the variation of stress drop with magnitude. Changes in the attenuation preferentially affect the stress drops inferred for smaller earthquakes, which modifies the dependence of stress drop on magnitude and the ground motions predicted for large future earthquakes.

In addition to the regional analyses of earthquakes in Quebec, Ontario, and the northeastern United States, we analyze nine $M_{\mathrm{w}}$ 3.5-5.0 earthquakes in Nunavut and northern Quebec to determine the $\mathrm{Lg}$ attenuation to distances of $1,700 \mathrm{~km}$. This far-regional attenuation allows us to analyze recordings of the $1989 M_{\mathrm{w}} 5.0$ Payne Bay, Quebec and the $M_{\mathrm{w}} 4.7$ and 6.2 Ungava, Quebec earthquakes at stations in Ontario and southern Quebec. Teleseismic analyses of the Ungava earthquake by Boatwright and Choy (1992) and Bent (1994) determined that the rupture was shallow, Adams and others (1991) mapped $8.5 \mathrm{~km}$ of surface faulting that exhibits both thrust and strike-slip offsets. There have been no teleseismic analyses of the 1989 Payne Bay earthquake.

This report is divided into four sections:

- The first section recaps the regional spectral model of Boatwright and Seekins (2011) and the modification required to incorporate $L g$ recordings on vertical components.

- The second section compares the moment magnitudes obtained from the regional spectral analysis with the moment magnitudes from the earthquake moment tensors determined by Bob Herrmann.

- The third section uses the RSA analysis to estimate $\mathrm{Lg}$ attenuation in seven separate regions within NENA.

- The last section calculates the corner frequencies, Brune (1970) stress drops, and radiated energies for the full catalog of earthquakes.

\section{Regional Spectral Analysis (RSA)}

Our analysis of the regional recordings follows Boatwright and Seekins (2011). We model the Fourier transforms of the $\mathrm{S}+\mathrm{Lg}$ waves as:

$$
|\dot{u}(r, \omega)|=\frac{\hat{F} F^{s} S_{I}(f)}{g\left(r, r_{o}\right)} \exp (-\pi f r / \beta Q) \frac{\ddot{M}_{o}(f)}{4 \pi \rho_{o} \beta_{o}^{3}}
$$


where $\hat{F}=2$ is the free-surface amplification, $S_{I}(f)$ is the site response, which includes the near-surface attenuation term, $\exp (-\pi \kappa f)$, proposed by Anderson and Hough (1984). Boatwright and Seekins (2011) found that $\kappa=0.005$ second (s) fit the average corrected spectra for the four earthquakes they analyzed. Our fits for these 118 additional earthquakes corroborate this estimate.

$F^{S}=0.55$ is the calculated radiation pattern for the square root of the sum of the squares of the horizontal components, we fit $F^{S}=0.31$ as the radiation pattern for the vertical component. Atkinson's (2004) analysis of the short-period vertical-component $L g$ recordings from the Canadian National Seismic Network (CNSN) stations demonstrated the utility of these recordings. These short-period stations complement the sparse network of 3-component CNSN and United States National Seismic Network (USNSN) stations.

Street and others, (1975) proposed the geometrical spreading function,

$$
g\left(r, r_{o}\right)=\left\{\begin{array}{cc}
r & r \leq r_{o} \\
r_{o}\left(r / r_{o}\right)^{\gamma} & r>r_{o}
\end{array}\right.
$$

where $r$ is the hypocentral distance and $r_{0}=100 \mathrm{~km}$ was the "crossover" distance. Boatwright and Seekins (2011) revised the crossover distance from 100 to $50 \mathrm{~km}$.

The exponential term $\exp (-\pi f r / \beta Q)$ contains the regional attenuation, which depends on the $L g$ group velocity $\beta=3.5$ kilometers per second $(\mathrm{km} / \mathrm{s})$ and the frequency-dependent quality factor $Q$. Boatwright and Seekins (2011) determined $Q=410 f^{0.5}$ for paths in New England and southeastern Quebec; they associate this $Q$ with the Appalachian province. In a later section, we estimate the $L g$ attenuation for seven separate regions in NENA.

The source term contains the moment rate spectrum $\dot{M}_{o}(f)$. In this analysis, we assume that the sources are isotropic, that is, they do not exhibit directivity. This assumption appears appropriate for most of the moderate thrust earthquakes analyzed, although some events exhibit directivity. Boatwright and Seekins (2011) use an average crustal density $\rho=2.8$ grams per cubic centimeter $\left(\mathrm{g} / \mathrm{cm}^{3}\right)$ and Swave velocity $\beta_{o}=3.8 \mathrm{~km} / \mathrm{s}$. In the next section, we adjust these parameters according to the source depth to fit the moment magnitudes from moment tensor inversions.

The regional spectral model described by equation 1 is physically appropriate and relatively simple, despite the number of coefficients. It is similar to the regional spectral models developed in Atkinson (2004) and Atkinson and Boore (2014) except that those papers use different geometrical spreading functions. While the different geometrical spreading functions predict stronger ground motions at close distance, they have little effect on the estimated attenuation or source spectra. As an example, using Atkinson's (2004) trilinear geometrical spreading instead of equation 2 for the earthquakes analyzed by Boatwright and Seekins (2011) yields a 5 percent stronger (lower Q) estimate of attenuation.

Equation 1 is used as the basis for the source, station, and attenuation inversion performed by Benz and others (1997) and Erickson and others, (2004). However, the inversion is more powerful if the station set is restricted to instruments sited on hard and firm rock, and the site amplifications are taken as either NEHRP A or B instead of inverted for.

We estimate the amplification for these sites from the velocity structures shown in figure 1 following the method of Boore and Joyner (1997). We check the relative amplification for each newly added station and assign the station to the hard- or firm-rock category, determine an appropriate frequency limit if the site appears to have a high-frequency resonance, or discard the recording.

Using average site response functions allows us to estimate the attenuation spectra directly as a function of frequency. We fit the Aki and Chouet (1975) $Q_{o} f^{\square}$ form to the attenuation estimates for 
events within a specific region and then use this fitted $Q_{o} f^{\eta}$ function to estimate the source spectra for earthquakes in that region.
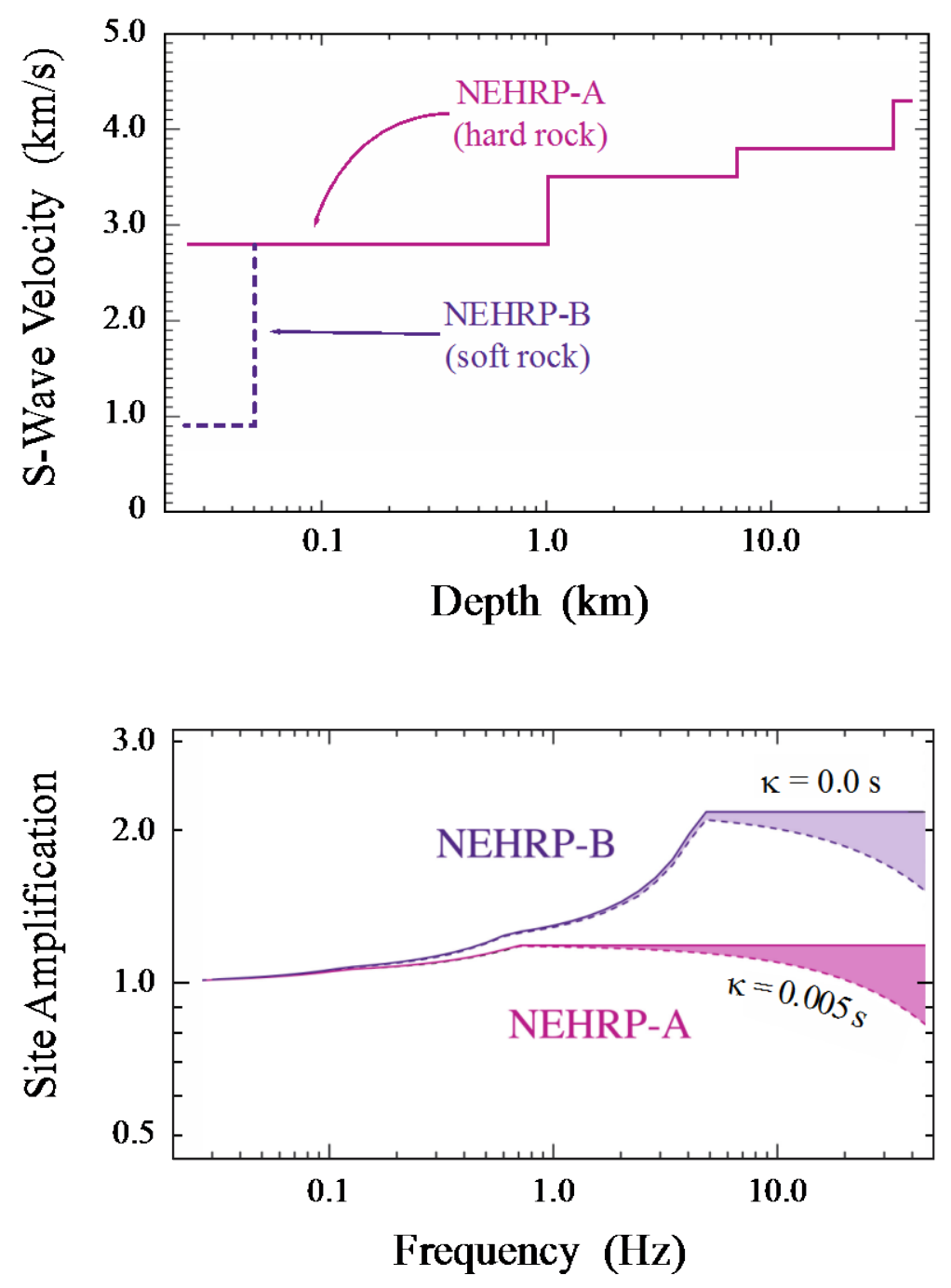

Figure 1. Graphs of S-wave velocity structures assumed for hard and firm-rock sites in northeastern North America, and the consequent amplifications plotted as functions of frequency, where the upper and lower limits of the shaded areas are determined by $\kappa=0.0$ and $0.005 \mathrm{~s}$. $\kappa$, near-surface attenuation; $\mathrm{km}$, kilometer; $\mathrm{km} / \mathrm{s}$, kilometers per second; $\mathrm{Hz}$, cycles per second.

This limited inversion is better posed than the source and station decomposition originally devised by Andrews (1986), which has been refined and implemented by many other authors. Specifically, the source and station decomposition is inherently unconstrained because the $S_{I}(f)$ and $\dot{M}_{o}(f)$ terms can tradeoff arbitrarily. This tradeoff is usually constrained by fitting the source spectra $\dot{M}_{o}(f)$ to an $\omega$-square spectra shape. In contrast, the linear dependence of attenuation on distance avoids any tradeoff between the source and attenuation spectra, allowing these quantities to be estimated directly as functions of frequency. 


\section{Comparing RSA Moments to Estimates from Moment Tensor Analyses}

To compare moment estimates from the regional spectral analysis with the moment tensor estimates published by Du and others (2003), Won-Young Kim (Lamont-Doherty Earth Observatory), and Bob Herrmann (St. Louis University), we determine RSA moment magnitudes using a simple tworegion attenuation model. We use Boatwright and Seekins' (2011) attenuation $Q=410 f^{0.5}$ for earthquakes in the Appalachian province, and the attenuation $Q=540 f^{0.45}$ for earthquakes in the Grenville province. We note that these attenuation functions are close to the average attenuation $Q=525 f^{0.45}$ determined by Atkinson and Boore (2014) for NENA.

To compare the RSA moments directly to moments from moment tensor analyses, we need to adjust the RSA moments to the parameters at the source depth. Fortunately, the values that Boatwright and Seekins (2011) chose for the crustal source density and S-wave velocity, $\rho_{o}=2.8 \mathrm{~g} / \mathrm{cm}^{3}$ and $\beta_{o}=3.8$ $\mathrm{km} / \mathrm{s}$, are close to Herrmann's model for the mid and lower crust in NENA. We determine depthdependent corrections for $M_{\mathrm{w}}$ by substituting (z)and $\beta(\mathrm{z})$ for $\rho_{o}$ and $\beta_{o}$ as

$$
d M_{w}=\frac{2}{3} \log \left(\frac{\rho(z) \beta^{3}(z)}{\rho_{o} \beta_{o}^{3}}\right)
$$

obtaining -0.057 for $h<10 \mathrm{~km},-0.018$ for $10 \leq h \leq 20 \mathrm{~km}$, and 0.018 for $h>20 \mathrm{~km}$. Won-Young Kim uses $\rho_{o}=2.7 \mathrm{~g} / \mathrm{cm}^{3}$ and $\beta_{o}=3.8 \mathrm{~km} / \mathrm{s}$ for the analyses of the 2000 Kipawa, 2002 Ausable Forks, and 2011 Youngstown earthquakes, so his $M_{\mathrm{w}}$ estimates should be 0.06 less than the RSA estimates. We use the same moment-magnitude relationship

$$
M_{w}=\frac{2}{3} \log \left(M_{o}\right)-16.1
$$

as Du and others, (2003), Boatwright and Seekins (2011), and Herrmann.

The regional spectral analysis is not automated. Microseismic noise in NENA is driven by storms in the North Atlantic. Events smaller than $M_{\mathrm{w}} \sim 4$ require the analyst to consider the signal versus noise levels to choose the limiting distance for stations to be included and the frequency band where the "long-period" level is fit. Figure 2 shows the fitting process for the largest aftershock of the 2002 Ausable Forks earthquake. The $f_{\min }$ for this spectrum, 0.7 cycles per second $(\mathrm{Hz})$, is relatively high for an $M_{\mathrm{w}} \sim 3.5$ earthquake, probably because it occurred only 14 minutes after the main shock. Using the $0.7-3 \mathrm{~Hz}$ frequency band gives an uncertainty of \pm 0.06 for the $M_{\mathrm{w}}$ estimate. This uncertainty is purely aleatory, as it is derived from the width of the uncertainty bounds for the fitted source spectral values. 


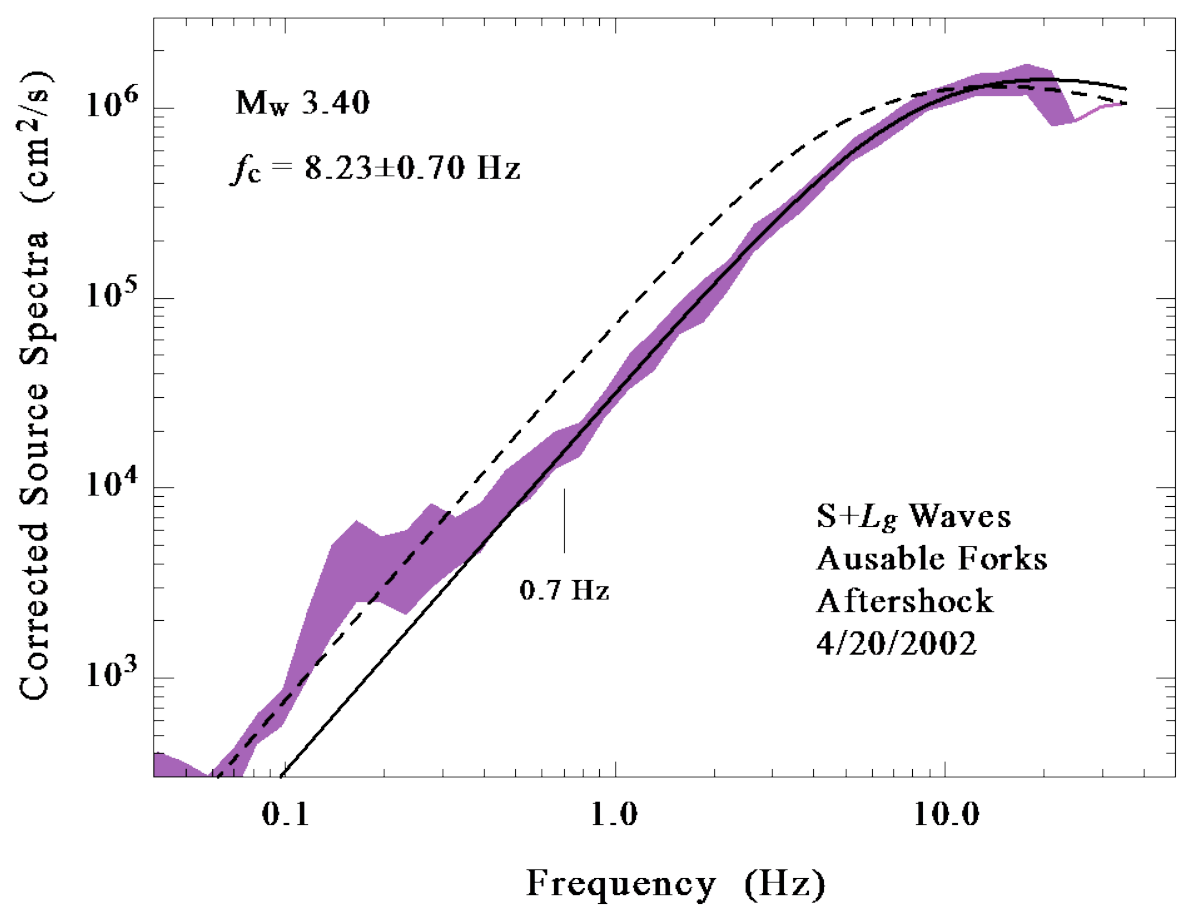

Figure 2. Graph displaying the spectral analysis of the moment magnitude $\left(M_{\mathrm{w}}\right) 3.4$ aftershock of the $M_{\mathrm{w}} 4.9$ Ausable Forks earthquake. The vertical lines at 0.7 and $3 \mathrm{~Hz}$ show the limits for the fit to the long-period level; the fitted $M_{w} 3.40$ Brune source spectrum is drawn as a solid line. The dashed spectrum shows the result of fitting the spectral amplitudes around $0.1 \mathrm{~Hz}$, which yields $M_{w} 3.65$ but misfits the spectral amplitudes from 0.3 to $7 \mathrm{~Hz} . \mathrm{cm}^{2} / \mathrm{s}$, centimeters per second; $f_{c}$, corner frequency; $\mathrm{Hz}$, cycles per second.

We leave the near-surface attenuation $\exp (-\pi \kappa f)$ in the corrected source spectrum and add it to the fitted Brune (1970) spectrum. Plotting the spectra in this fashion allows us to consider the spectral shape that the estimate $\kappa=0.005 \mathrm{~s}$ yields.

Table 1 compares the estimates of moment magnitude for 50 earthquakes.

Table 1. Moment magnitude $\left(M_{\mathrm{w}}\right)$ estimates from moment tensor and regional spectral analyses (RSA). [SLU, (St. Louis University) $M_{\mathrm{w}}$ estimates from Bob Herrmann; LD, (Lamont-Doherty Earth Observatory) $M_{\mathrm{w}}$ estimates from Du and others (2003) and Won-Young Kim; WO, (Western Ontario) $M_{\mathrm{w}}$ estimates from Atkinson (2004); fmin, minimum frequency; km, kilometers; Hz, cycles per second; FS, foreshock; AF, aftershock. Names are from the Canadian catalog, with some interpolations]

\begin{tabular}{|c|c|c|c|c|c|c|c|}
\hline Earthquake & Date & $\begin{array}{c}\text { Depth } \\
(\mathrm{km})\end{array}$ & $M_{w}(\mathrm{SLU})$ & $M_{w}(L D)$ & $M_{w}(\mathrm{WO})$ & $M_{w}(\mathrm{RSA})$ & $\begin{array}{l}f \min \\
(\mathrm{Hz})\end{array}$ \\
\hline Stark, NY & 9/26/87 & 5 & & & 3.42 & 3.29 & 0.7 \\
\hline Baie-des-Chaleurs, QC & $1 / 28 / 88$ & 18 & & & 3.62 & 3.73 & 0.5 \\
\hline Berlin, NH & $10 / 20 / 88$ & 5 & & & 3.55 & 3.47 & 0.7 \\
\hline Saguenay FS & 11/23/88 & 29 & & & 4.26 & 4.22 & 0.4 \\
\hline Saguenay, QC & $11 / 25 / 88$ & 29 & & & & 5.80 & 0.05 \\
\hline Saguenay AS & 11/26/88 & 26 & & & 3.57 & 3.55 & 0.5 \\
\hline Saguenay AS2 & $1 / 19 / 89$ & 25 & & & 3.30 & 3.20 & 0.4 \\
\hline Harve-St-Pierre, QC & 2/10/89 & 10 & & & 3.91 & 3.82 & 0.7 \\
\hline
\end{tabular}




\begin{tabular}{|c|c|c|c|c|c|c|c|}
\hline Earthquake & Date & $\begin{array}{c}\text { Depth } \\
(\mathrm{km})\end{array}$ & $M_{w}(\mathrm{SLU})$ & $M_{\mathrm{w}}(\mathrm{LD})$ & $M_{\mathrm{w}}(\mathrm{WO})$ & $M_{\mathrm{w}}(\mathrm{RSA})$ & $\begin{array}{l}\text { fmin } \\
(\mathrm{Hz})\end{array}$ \\
\hline Ungava AS & $12 / 15 / 89$ & 5 & & & 4.57 & 4.77 & 0.3 \\
\hline Mont-Laurier, QC & 10/19/90 & $11 *$ & & 4.57 & 4.49 & 4.42 & 0.1 \\
\hline Napierville, QC & $11 / 16 / 93$ & $12 *$ & & 3.84 & & 3.56 & 0.5 \\
\hline Reading, PA & $1 / 16 / 94$ & $2^{*}$ & & 4.55 & & 4.59 & 0.05 \\
\hline Lisbon, NH & 6/16/95 & $3^{\wedge}$ & & 3.70 & & 3.36 & 0.5 \\
\hline Lachute, QC & $3 / 14 / 96$ & $18^{*}$ & & 3.71 & & 3.58 & 0.3 \\
\hline Berlin, NH & $8 / 21 / 96$ & $7^{*}$ & & 3.44 & & 3.39 & 0.5 \\
\hline Nunavit, NU & $12 / 6 / 97$ & $10 \dagger$ & 5.07 & & & 5.03 & 0.05 \\
\hline La Malbaie, QC & 10/28/97 & 11 & & 4.26 & & 3.96 & 0.4 \\
\hline Cap-Rouge, QC & 11/6/97 & $22 \dagger$ & 4.38 & 4.47 & 4.22 & 4.42 & 0.05 \\
\hline Mont-Tremblant, QC & 7/30/98 & $12 *$ & & 3.70 & 3.93 & 3.61 & 0.4 \\
\hline Pymatuning, PA & 9/25/98 & $2^{*}$ & & 4.53 & 4.76 & 4.56 & 0.07 \\
\hline Lower St. Lawrence, QC & 10/22/98 & 18 & & & 3.50 & 3.39 & 0.5 \\
\hline Waterville, ME & 2/26/99 & 18 & & & 3.58 & 3.45 & 0.5 \\
\hline Ste-Anne-des-Monts, QC & $3 / 16 / 99$ & $18^{*}$ & & 4.39 & 4.50 & 4.36 & 0.3 \\
\hline Saint-Jerome, QC & 10/31/99 & 18 & & & 3.44 & 3.21 & 0.5 \\
\hline Kipawa, QC & $1 / 1 / 00$ & $13^{*}$ & & 4.58 & 4.54 & 4.55 & 0.05 \\
\hline Newcomb, NY & $4 / 20 / 00$ & 8* & & 3.62 & 3.68 & 3.47 & 0.4 \\
\hline Grands Jardins, QC & $7 / 12 / 00$ & 18 & & & 3.64 & 3.35 & 0.5 \\
\hline Ashtabula, $\mathbf{O H}$ & $1 / 26 / 01$ & $2 *$ & & 3.85 & 4.04 & 3.83 & 0.25 \\
\hline Ausable Forks, NY & $4 / 20 / 02$ & $11 \dagger$ & 4.97 & 5.03 & 4.84 & 4.94 & 0.05 \\
\hline Ausable AS & $4 / 20 / 02$ & $11^{*}$ & & 3.66 & 3.55 & 3.38 & 0.7 \\
\hline Pointe-de-Monts, QC & $1 / 20 / 02$ & 30 & & & 3.48 & 3.43 & 0.5 \\
\hline Radisson, QC & $6 / 5 / 02$ & $2 \dagger$ & 3.64 & & 3.84 & 3.77 & 0.05 \\
\hline Sept-Iles, QC & $7 / 23 / 02$ & 22 & & & 3.50 & 3.61 & 0.5 \\
\hline Caps-Saint-Fidèle, QC & $6 / 13 / 03$ & $11 \dagger$ & 3.34 & & 3.52 & 3.41 & 0.3 \\
\hline Port Hope, ON & $8 / 4 / 04$ & $5 \dagger$ & 3.19 & 3.09 & & 3.04 & 1.0 \\
\hline Southampton, NU & $8 / 26 / 04$ & $23 \dagger$ & 4.24 & & & 4.22 & 0.2 \\
\hline Rivière-du-Loup, QC & $3 / 6 / 05$ & $15^{*}$ & 4.57 & & & 4.62 & 0.05 \\
\hline Owen Sound, ON & $10 / 20 / 05$ & $10 \dagger$ & 3.61 & & & 3.54 & 0.3 \\
\hline Thurso, QC & $2 / 25 / 06$ & $16 \dagger$ & 3.62 & & & 3.55 & 0.3 \\
\hline L'Ile-aux-Coudres, QC & $4 / 7 / 06$ & $25 \dagger$ & 3.77 & & & 3.62 & 0.4 \\
\hline Eagle Lake, ME & $7 / 14 / 06$ & 5 & 3.48 & & & 3.39 & 0.3 \\
\hline Bar Harbor, ME & 10/3/06 & $2 \dagger$ & 3.87 & & & 3.90 & 0.07 \\
\hline Rivière AS & $11 / 15 / 08$ & $14 \dagger$ & 3.57 & & & 3.47 & 0.4 \\
\hline Mansel Island, QC & 3/21/09 & $1 \dagger$ & 3.78 & & & 3.84 & 0.06 \\
\hline Sept-Iles, QC & $7 / 21 / 09$ & $15 \dagger$ & 3.54 & & & 3.61 & 0.08 \\
\hline Val-des-Bois, QC & $6 / 23 / 10$ & 22 & 5.04 & & & 5.06 & 0.05 \\
\hline Hawkesbury, QC & $3 / 16 / 11$ & $11 \dagger$ & 3.45 & & & 3.45 & 0.4 \\
\hline Malone, NY & $8 / 24 / 11$ & $2 \dagger$ & 3.03 & & & 2.96 & 0.8 \\
\hline Youngstown, $\mathrm{OH}$ & $12 / 31 / 11$ & $4 *$ & 3.75 & 3.88 & & 3.76 & 0.5 \\
\hline Happy Valley, NL & 7/8/12 & $14 \dagger$ & 3.81 & & & 3.82 & 0.08 \\
\hline Waterboro, ME & $10 / 16 / 12$ & $7 \dagger$ & 4.03 & & & 4.10 & 0.4 \\
\hline Shawville, ON & $5 / 17 / 13$ & $13 \dagger$ & 4.49 & & & 4.54 & 0.05 \\
\hline Moisie, QC & $9 / 21 / 13$ & $27 \dagger$ & 3.96 & & & 3.87 & 0.3 \\
\hline Cap Chat, QC & $1 / 16 / 15$ & $19 \dagger$ & 3.65 & & & 3.69 & 0.3 \\
\hline Galesburg, MI & $5 / 3 / 15$ & $5 \dagger$ & 4.24 & & & 4.20 & 0.05 \\
\hline Yarmouth, NS & $7 / 1 / 15$ & $12 \dagger$ & 3.47 & & & 3.46 & 0.07 \\
\hline
\end{tabular}

$\dagger$ and * indicate depths are taken from the SLU and LD moment tensor analyses, respectively. $\wedge$ indicates the depth is estimated from the S-P time at a nearby station. Depths without symbols are taken from the Canadian earthquake catalog. 
The 2001 Ashtabula, 2011 Youngstown, and 2015 Galesburg earthquakes have strike-slip mechanisms, the other earthquakes have thrust mechanisms, we cannot test if the differences in $M_{\mathrm{w}}$ depend on mechanism. To consider if there is a bias with source depth or magnitude, we plot differences in the $M_{\mathrm{w}}$ estimates against these parameters in figures 3 and 4 . The differences between the $M_{\mathrm{w}}$ estimates from Bob Herrmann (http://www.eas.slu.edu/eqc/eqc_mt/MECH.NA/) (SLU) and RSA estimates for 27 events are colored red and show a slight dependence on both depth and $M_{\mathrm{w}}$.

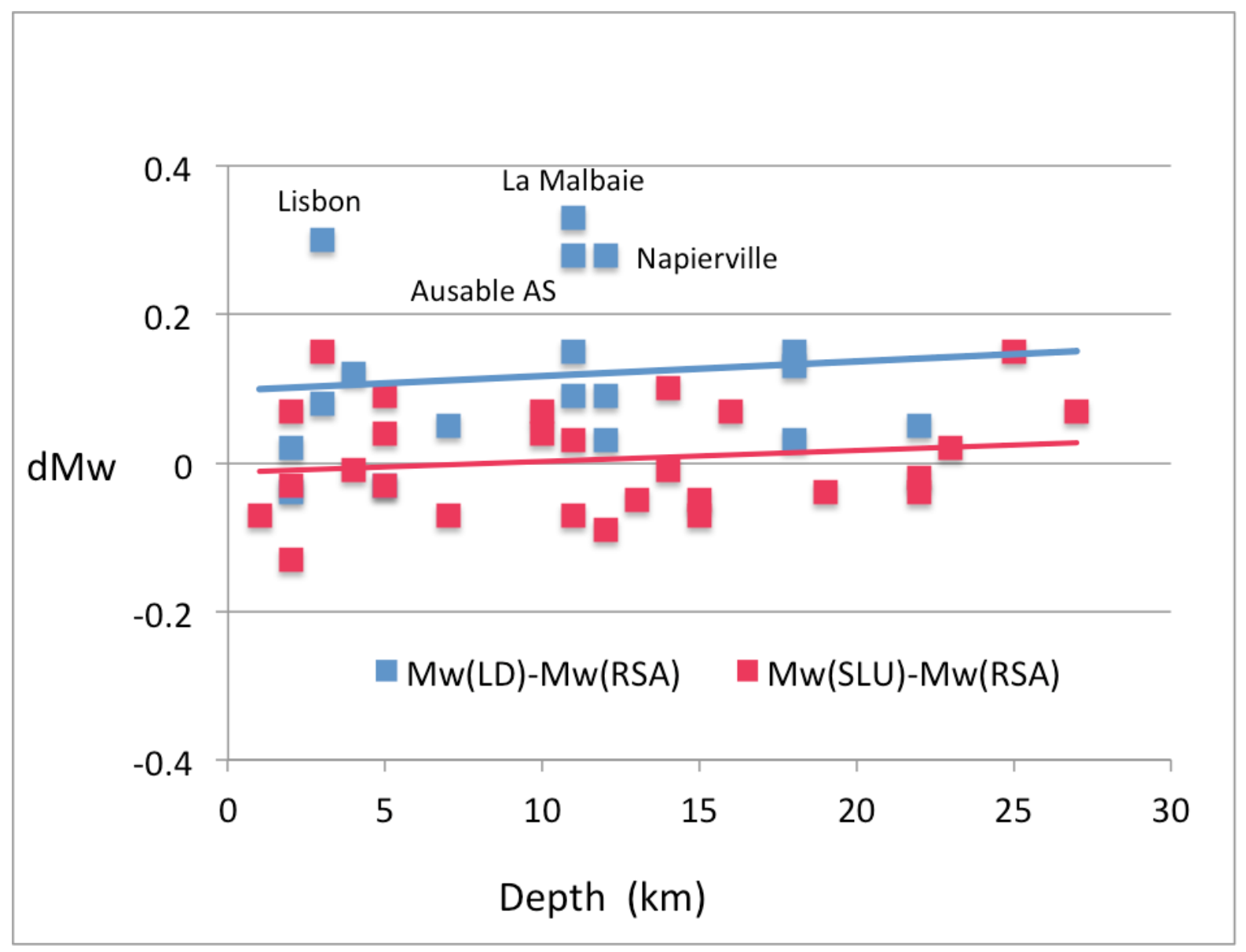

Figure 3. Graph showing moment magnitude $(M \mathrm{w})$ differences ( $\mathrm{d} M \mathrm{w}$ ) (red for SLU, blue for $L D)$ plotted as a function of source depth. The lines show linear fits to the differences. SLU, $M_{\mathrm{w}}$ estimates from Bob Herrmann (St. Louis University); LD, $M_{w}$ estimates from Du and others (2003) and Won-Young Kim (Lamont-Doherty Earth Observatory); km, kilometer. 


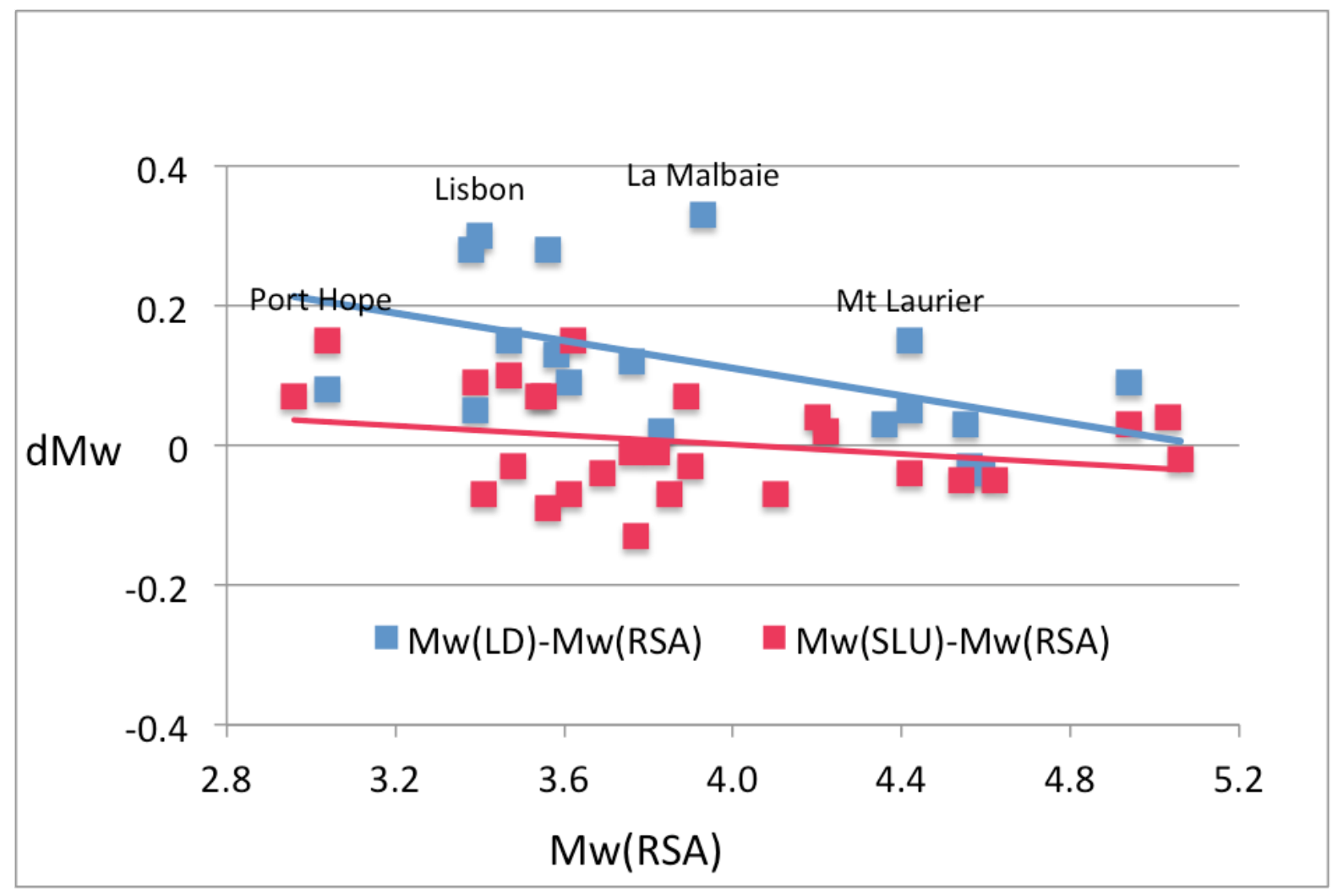

Figure 4. Graph showing moment magnitude $\left(M_{\mathrm{w}}\right)$ differences (dMw) (red for SLU, blue for $\left.L D\right)$ plotted as a function of regional spectral analysis (RSA) Mw. SLU, $M_{w}$ estimates from Bob Herrmann (St. Louis University); LD, $M_{\mathrm{w}}$ estimates from Du and others (2003) and Won-Young Kim (Lamont-Doherty Earth Observatory).

Overall, the comparison with the SLU moment magnitudes is remarkably close, The average difference in moment magnitudes is $\mathrm{d} M_{\mathrm{w}}=0.004 \pm 0.074$. We label a single outlier with respect to the SLU estimates, the 2004 Port Hope earthquake. It is the second smallest NENA earthquake in the SLU event set; we used an $f_{\max }=1.0 \mathrm{~Hz}$ in our analysis of this event.

The differences for the 18 events with $M_{\mathrm{w}}$ estimates from Du and others (2003) and Won-Young Kim (LD) are colored blue in figures 3 and 4 . We label four outliers with respect to Du and others, (2003) and Kim estimates. The discrepancies for the Napierville, Lisbon, and La Malbaie earthquakes and the Ausable Forks aftershock are substantial— $\mathrm{dMw} \sim 0.3$ corresponds to a factor of 3 in seismic moment. We note that the low-frequency limits that we use to estimate the seismic moments for these four events are relatively high, $f_{\max }=0.5-0.7 \mathrm{~Hz}$.

The 1990 Mont Laurier earthquake was the earliest event that Du and others, (2003) analyzed, they fit recordings from only two stations. The RSA $M_{\mathrm{w}}=4.42$ estimate is less than the estimates from Johnston (1996), Du and others, (2003), Atkinson (2004), and Boore and others, (2010) of $M_{\mathrm{w}}=4.56$, $4.54,4.49$, and 4.7 , respectively. Figure 5 shows that the corrected spectra from the broadband stations HRV and SCP and the long period WWSSN station WES, which are Appalachian stations, correspond adequately with the spectra from the short-period CNSN stations, which are mostly within the Grenville province. We note that the Mont Laurier earthquake exhibits directivity; the corrected spectra observed at stations to the east are enhanced from 1 to $4 \mathrm{~Hz}$ by factors of $2-3$ relative to those observed at stations to the west. This difference is muted in the averages shown above. 


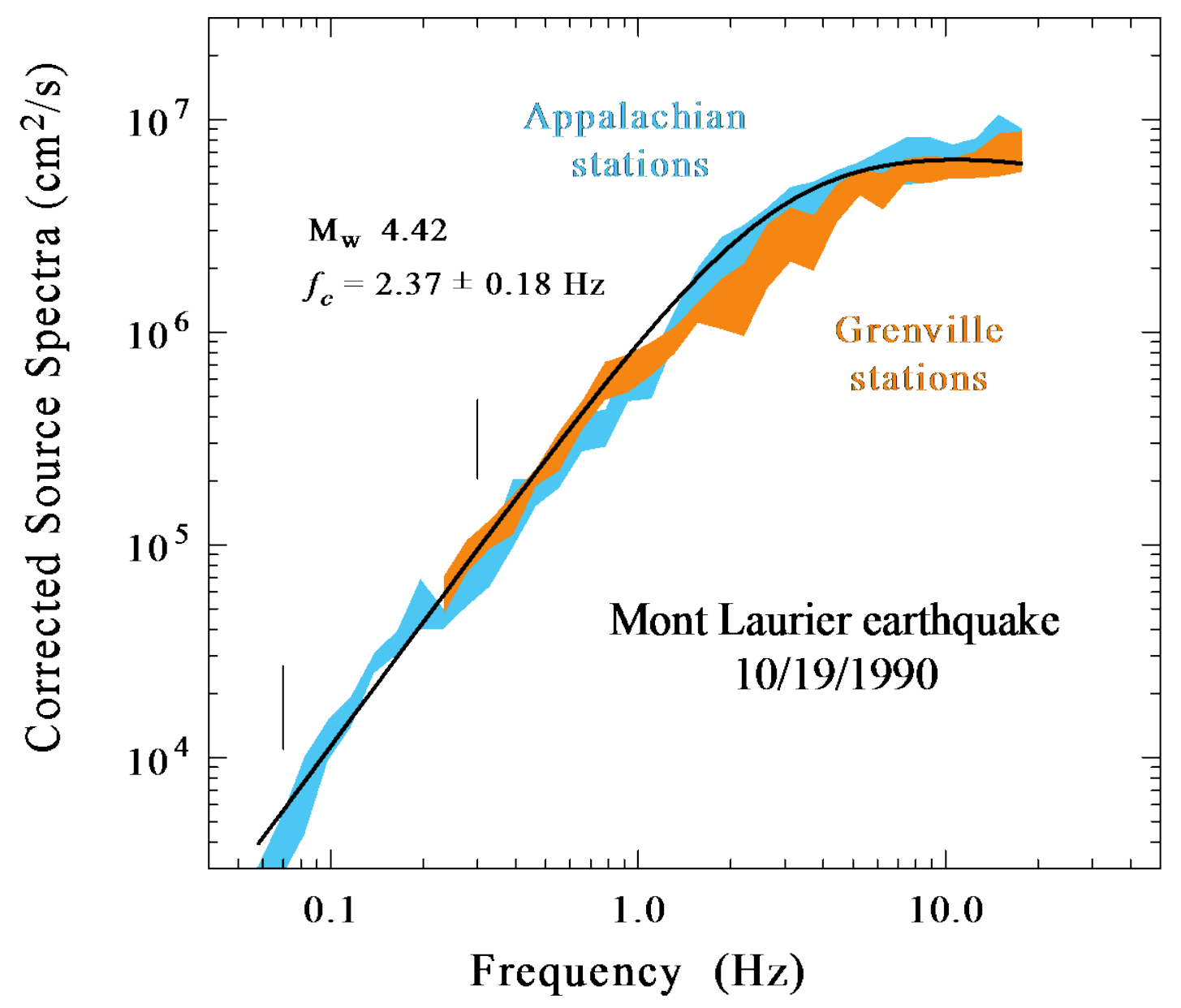

Figure 5. Graph of the spectral analysis of the 1990 Mont Laurier earthquake. The vertical lines indicate the low and high-frequency limits $(0.07-0.3 \mathrm{~Hz})$ for the estimate of the long-period level. The fitted Brune (1970) spectrum is drawn as a solid line. The blue and orange areas are spectral averages for the Appalachian and Grenville stations, respectively. $\mathrm{cm}^{2} / \mathrm{s}$, centimeters per second; $M_{\mathrm{w}}$, moment magnitude; $f_{\mathrm{c}}$, corner frequency; $\mathrm{Hz}$, cycles per second.

As an additional test of our moment magnitudes, we compare the RSA estimates with Atkinson's (2004) moment magnitudes for 26 earthquakes in New York, New England, and Quebec occurring from 1986 to 2003. As described above, Atkinson (2004) uses a similar model to analyze the spectral data analyzed in this report, but with a different geometrical spreading factor and different site amplifications. The comparison between these moment magnitudes is plotted as a function of $M_{\mathrm{w}}(\mathrm{RSA})$ in figure 6.

The marked difference between the moment magnitude estimates for the smaller earthquakes suggests that Atkinson's (2004) estimates of the long-period levels for the smaller events may be inflated by low-frequency noise. This noise would also serve to decrease estimates of the $L g$ attenuation (increase $Q$ ) at low frequencies, as figure 6 of Atkinson (2004) shows. The attenuation estimates that we obtain and fit in the next section do not exhibit this behavior. 


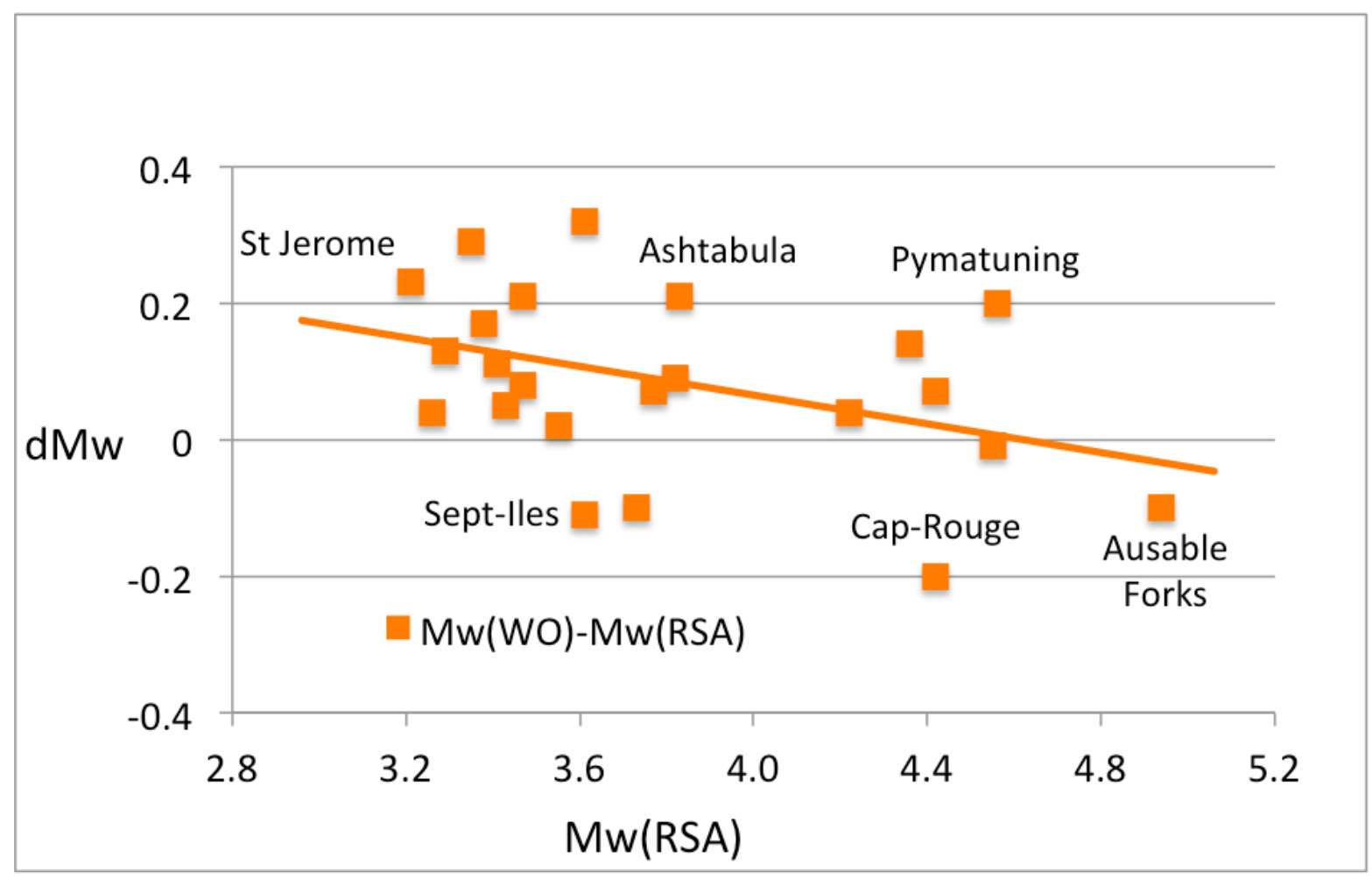

Figure 6. Graph of moment magnitude differences (dMw) between the Atkinson (2004) and regional spectral analysis (RSA) estimates plotted as a function of regional spectral analysis (RSA) moment magnitude (Mw). WO, Western Ontario.

\section{Summary}

Table 1 compares an extensive set of moment magnitude estimates for NENA earthquakes. It is useful to consider what these comparisons imply for the different elements of the regional spectral model. First, the correspondence with the SLU estimates certifies that Boatwright and Seekins' (2011) geometrical spreading function, with a crossover distance of $r_{o}=50 \mathrm{~km}$, is appropriately calibrated for regional recordings. This calibration can then be used to gauge other geometrical spreading functions, such as the models proposed by Street and others, (1975), Atkinson and Mereu (1992), Atkinson (2004), and Atkinson and Boore (2014).

Second, the correspondence validates the site amplifications that Boatwright and Seekins (2011) use for hard- and firm-rock stations, shown in figure 1 . In general, $f_{\min }$ increases as earthquake size decreases, so that the frequency range used to estimate the long-period levels is higher for smaller earthquakes. If the site amplifications calculated by Boatwright and Seekins (2011) systematically underestimated the actual site amplifications, we would expect $M_{\mathrm{w}}(\mathrm{SLU})-M_{\mathrm{w}}(\mathrm{RSA})$ to decrease for smaller earthquakes, instead of increasing slightly.

\section{S+Lg Attenuation in Northeastern North America}

The $L g$ phase dominates regional seismograms in northeastern North America. $L g$ develops from the near-source S-waves as a superposition of incoherent phases that have been reflected and scattered within the crust. This ensemble of scattered arrivals carries most of the energy from the earthquake to 
regional distances. For distances beyond $500 \mathrm{~km}$, the attenuation in the crust progressively reduces $\mathrm{Lg}$ relative to $S n$, which is refracted through the uppermost mantle.

Unfortunately, this conceptually simple propagation model has not produced a consensus model for $L g$ attenuation in NENA. Twenty-five years of attenuation studies and a variety of different methods have obtained a wide range of estimates for $L g$ attenuation. Fully explaining these differences is beyond the scope of this report, but we compare our estimates with earlier results throughout this section.

Boatwright and Seekins' (2011) estimate of $Q=410 f^{0.5}$ for $L g$ attenuation was stronger ( $Q$ is lower) than previous estimates for NENA. They suggest that this difference is the result of their analyzing $M_{\mathrm{w}}>4$ earthquakes, which improves the signal to noise ratio. In addition, they only used stations within $600 \mathrm{~km}$ of the earthquakes to avoid distortion from the $S n$ phase. Atkinson and Boore (2014) only use stations within $500 \mathrm{~km}$ of $M_{\mathrm{w}} \geq 3.5$ earthquakes to estimate an average attenuation of $Q=525 f^{0.45}$ for NENA.

Because the distribution of raypaths for these events does not sufficiently cover all of Ontario, Quebec, and the northeastern United States, we estimate the attenuation within seven separate regions within this area. Two conditions shape these regions: the distribution of earthquakes and stations, and the variation of the attenuation observed event by event. Once the different regions are selected, we group events and stations whose raypaths sample these regions.

We estimate the $L g$ attenuation in Charlevoix, lower St. Lawrence, Maine, northern New York, lower Great Lakes, Ontario, and Nunavut. These names are chosen for convenience: they are not geographically exact. Three of the regions are the same as the regions studied by Woodgold (1990) using a coda-Q analysis. The distribution of events and stations in the Nunavut region allows us to estimate $\mathrm{Lg}$ attenuation both within $600 \mathrm{~km}$, and from 500 to 1,700 km.

\section{Charlevoix}

The Charlevoix region is the most active source area in NENA. The CNSN deployed seven 3component short-period stations in Charlevoix in the 1980s that were upgraded to broadband in 1994. We include 10 moderate earthquakes in the analysis: the raypaths for these events are plotted in figure 7. The earthquakes range in size, $M_{\mathrm{w}}$ 3.4-5.8, the 1988 Saguenay earthquake is the largest. Because the Appalachian-Grenville boundary follows the St. Lawrence River, we do not use stations to the north of the Charlevoix earthquakes. 


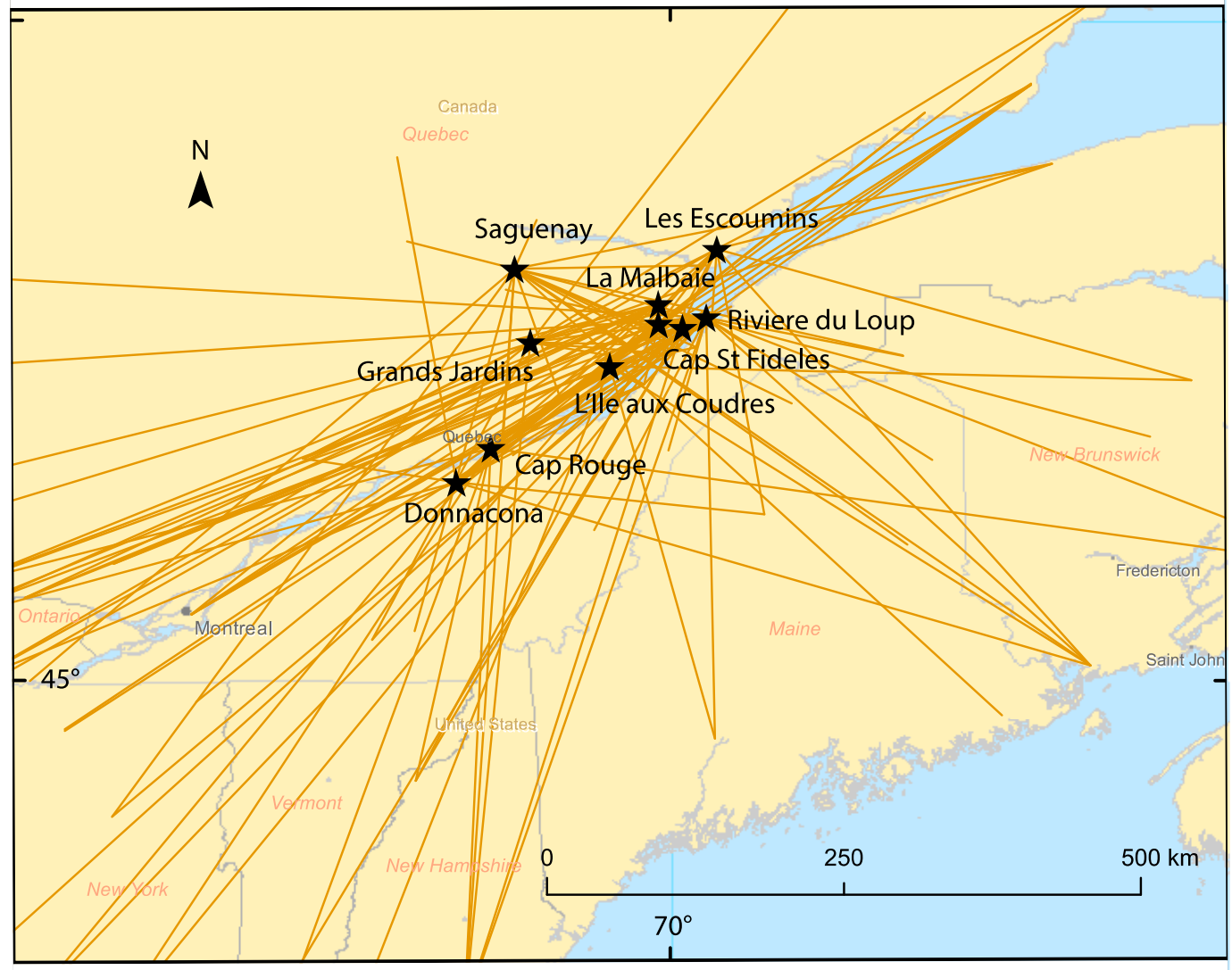

Figure 7. Map of raypaths for the Charlevoix region.

The resulting attenuation estimates are shown in figure 7, and compared to Atkinson and Boore's (2014) NENA average and Woodgold's (1990) estimates for her Region C. The estimates agree reasonably with the earlier results, although Woodgold's (1990) coda-Q estimates increase more rapidly with frequency. Fitting the Aki and Chouet (1975) function to the attenuation estimates from 0.2 to 20 Hz yields $Q=(363 \pm 15) f^{(0.54 \pm 0.02)}$. The $Q_{o} f^{\eta}$ functional form fits the attenuation closely over two decades of frequency, in contrast to the previous results of Benz and others, (1997), Atkinson (2004), Erickson and others, (2004), and Atkinson and Boore (2014). 


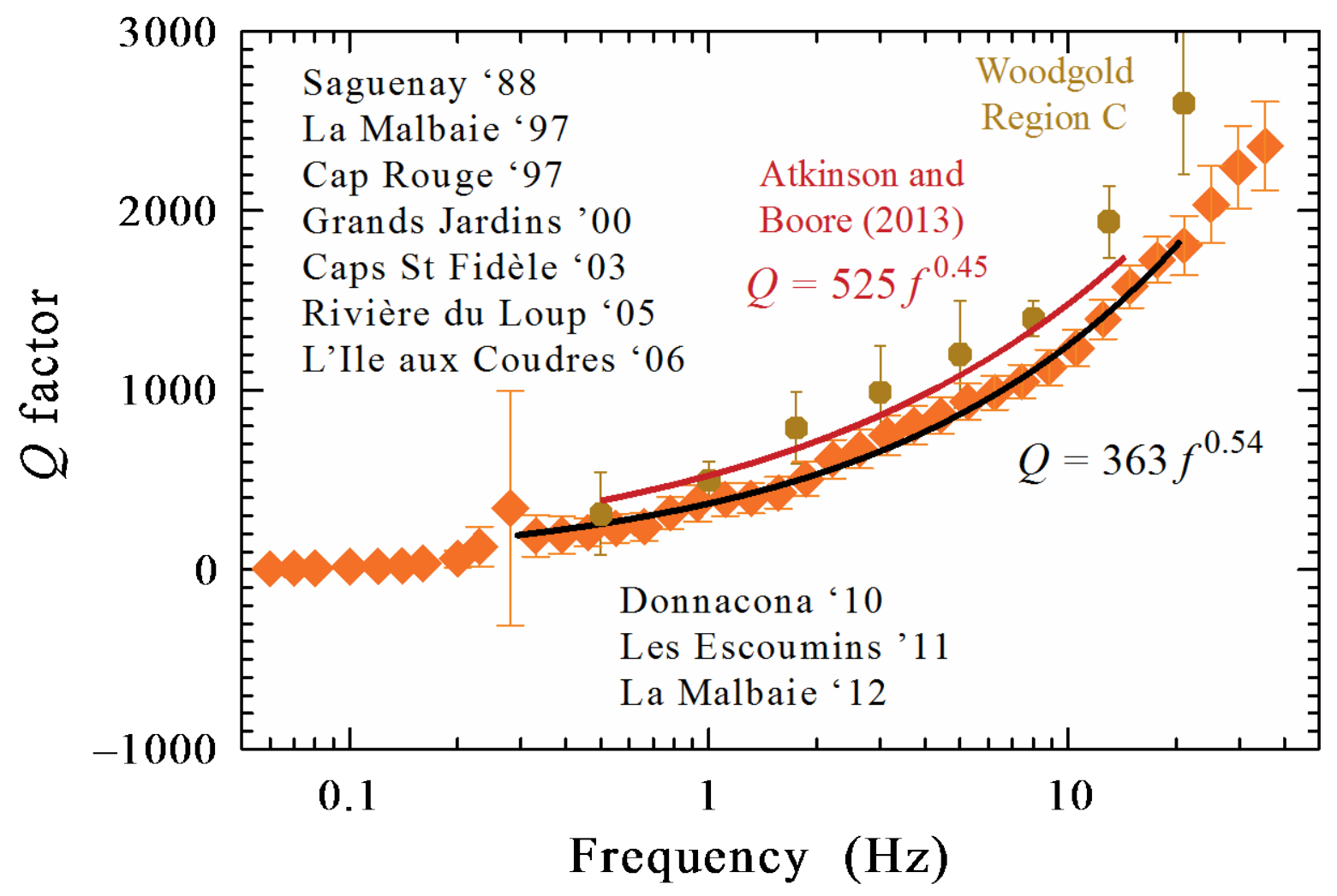

Figure 8. Graph of attenuation estimates from 10 earthquakes in Charlevoix and southeastern Quebec, fit from 0.2 to $20 \mathrm{~Hz}$. Q, quality factor; $\mathrm{Hz}$, cycles per second; $f$, frequency.

\section{Lower St. Lawrence}

The lower St. Lawrence region is less active than Charlevoix, and the CNSN stations are less dense. Most of the stations in the region have short-period vertical instruments. We include seven moderate earthquakes in the attenuation analysis, the raypaths for these events are plotted in figure 9. The earthquakes range in size, $M_{\mathrm{w}}$ 3.5-4.4, the 1999 Ste-Anne-des-Monts earthquake is the largest. 


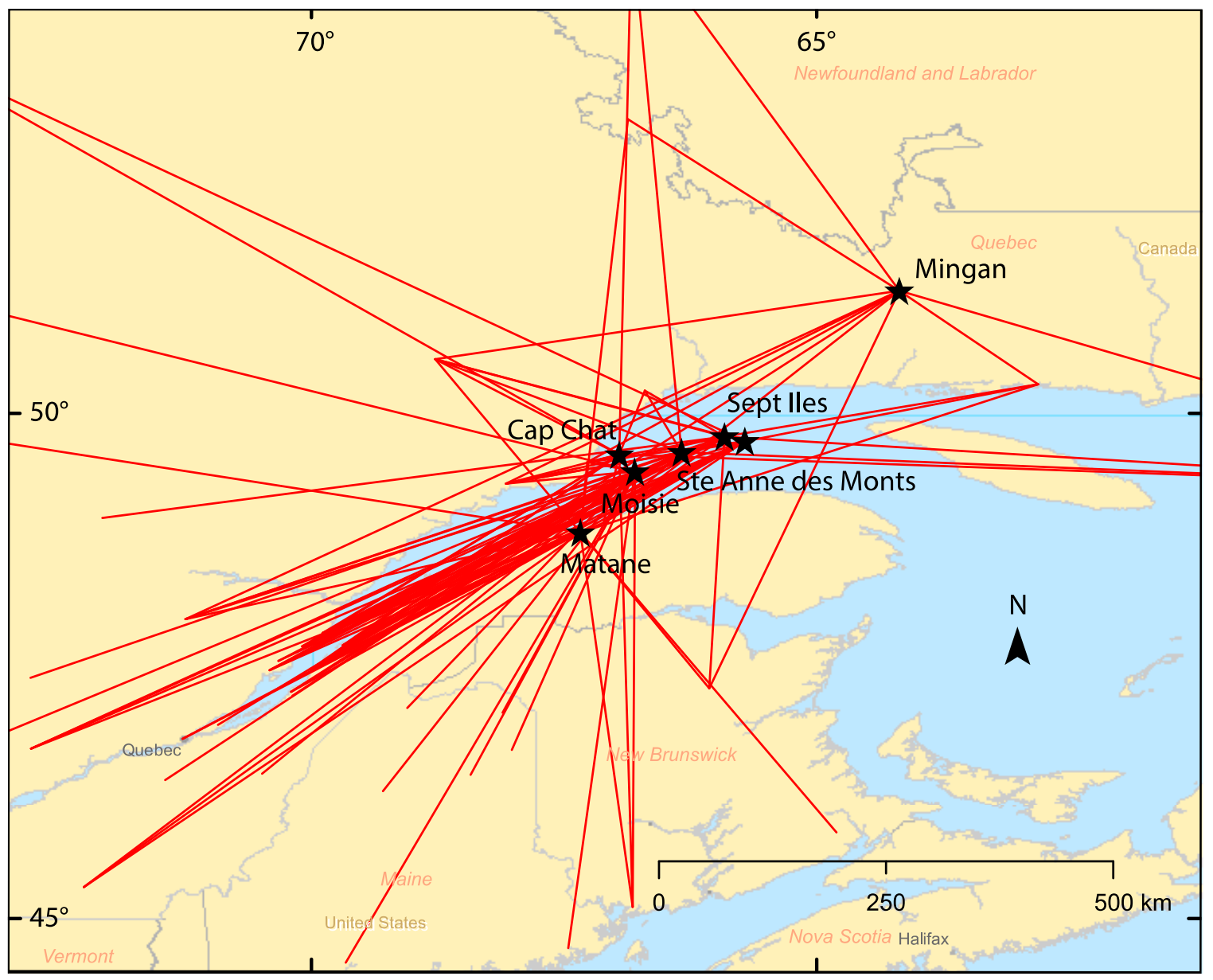

Figure 9. Map of raypaths for lower St. Lawrence earthquakes. The 23 July, 2002 and 21 July, 2009 earthquakes in the St. Lawrence Seaway are both labeled "Sept-Iles."

The attenuation estimates plotted in figure 10 are very similar to the attenuation estimates from Charlevoix. Fitting these estimates to the Aki and Chouet (1975) function from 0.2 to $20 \mathrm{~Hz}$ yields $Q=(381 \pm 24) f^{(0.55 \pm 0.03)}$. The correspondence with Shin and Hermann's (1987) and Woodgold's (1990, Region D) estimates is striking but not corroborative, as New Brunswick is south of the lower St. Lawrence. 


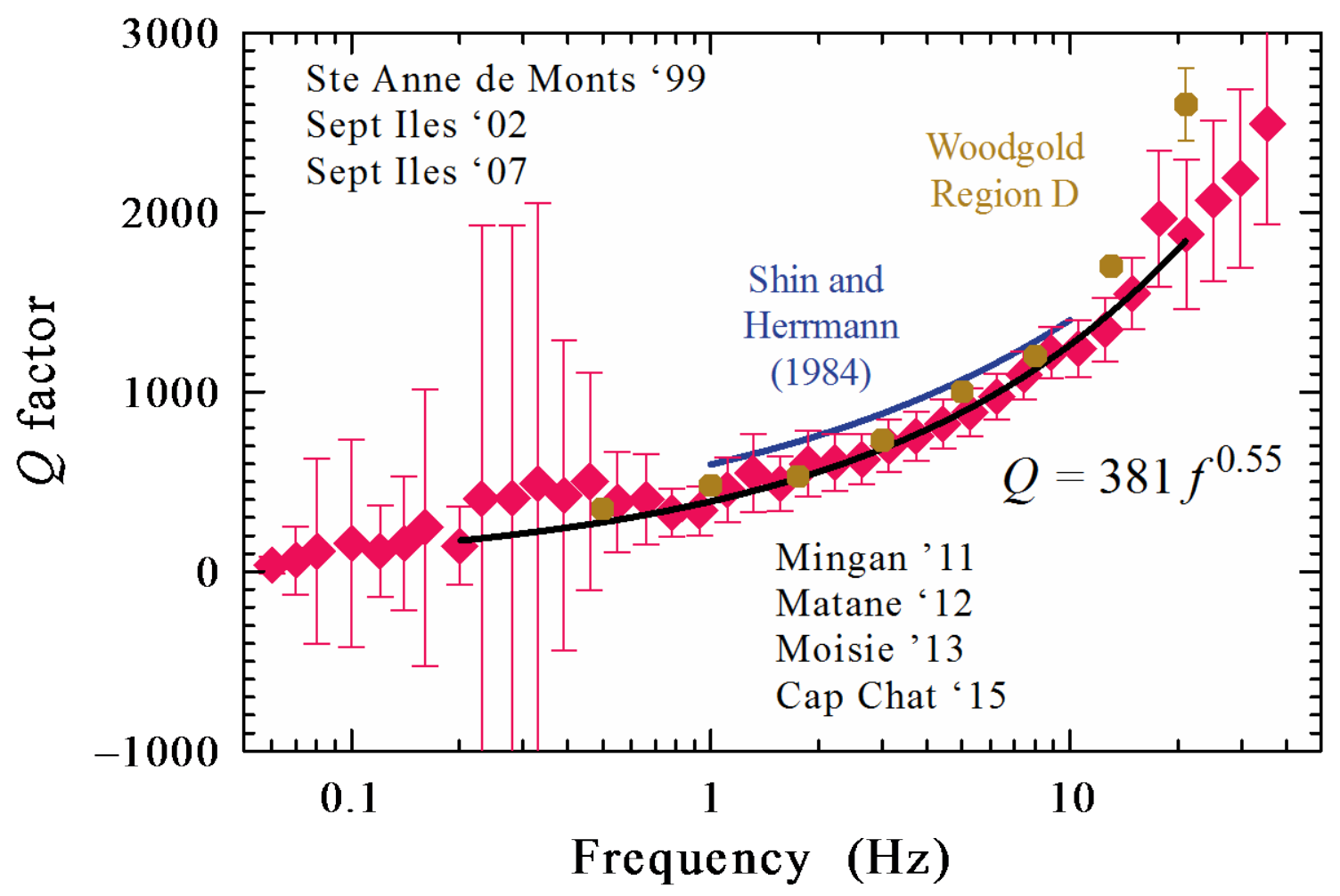

Figure 10. Graph of attenuation estimates from 7 earthquakes in the lower St. Lawrence area, fit from 0.2 to 20 $\mathrm{Hz}$. The estimates from Shin and Herrmann (1987) and Woodgold (1990) were obtained from analyses of earthquakes in New Brunswick. Q, quality factor; $\mathrm{Hz}$, cycles per second; $f$, frequency.

\section{Maine}

Maine is less active than Charlevoix and the lower St. Lawrence, but a number of moderate earthquakes have occurred in this region over the last 20 years. The New England Seismic Network (NESN) has deployed broadband instruments in Maine since the 1990s. We analyze five moderate earthquakes, ranging in size, $M_{\mathrm{w}}$ 3.4-4.1, the 2012 Waterboro earthquake is the largest. The raypaths for these events are plotted in figure 11. 


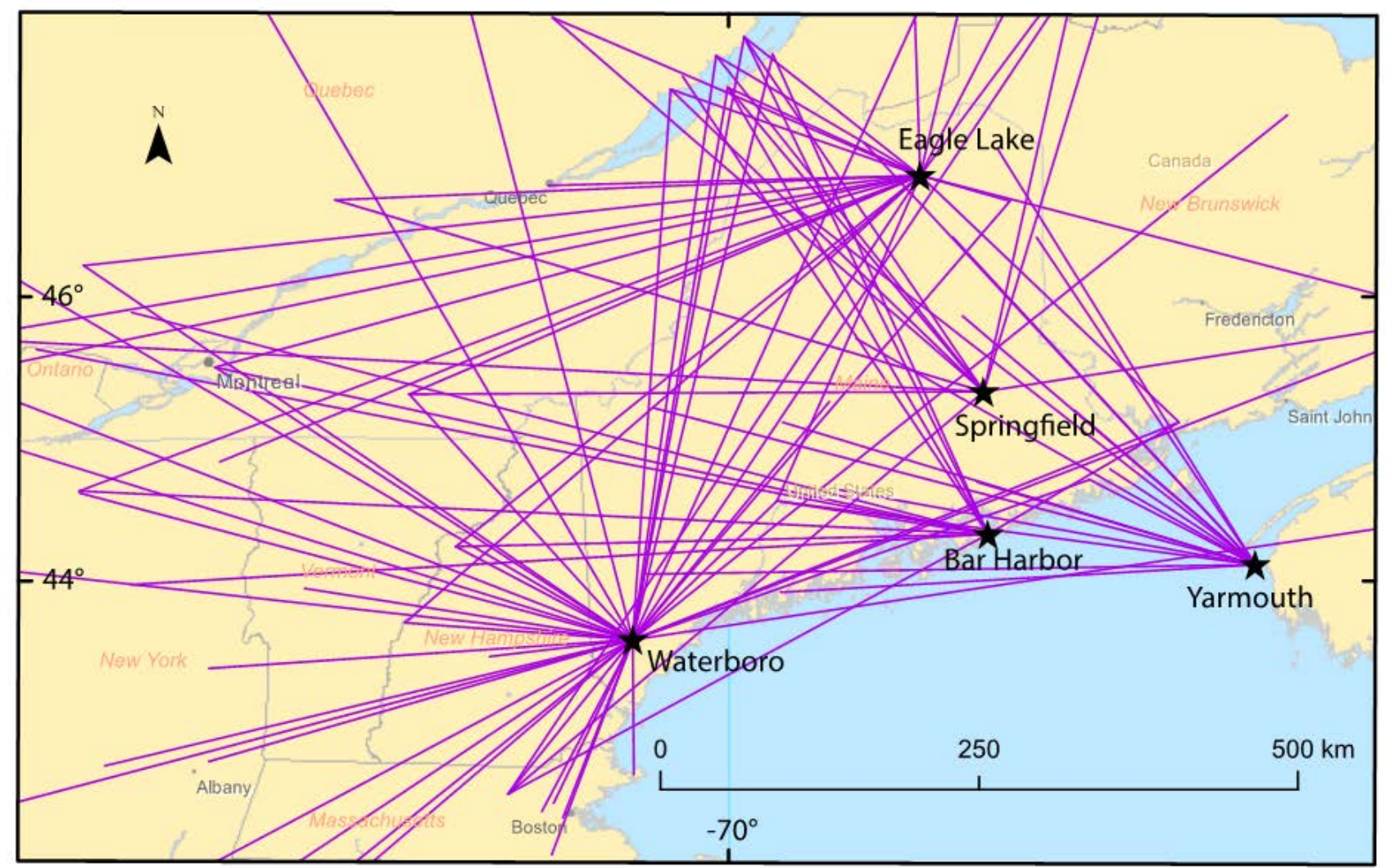

Figure 11. Map of raypaths for five Maine earthquakes.

The attenuation in Maine appears stronger ( $Q$ is lower) than the attenuation in Charlevoix or the lower St. Lawrence. Fitting these estimates to the Aki and Chouet (1975) function from 0.2 to $20 \mathrm{~Hz}$ yields $Q=(317 \pm 16) f^{(0.51 \pm 0.03)}$. This attenuation is well resolved, although the five earthquakes are somewhat smaller than the events used to analyze the attenuation in other regions. 


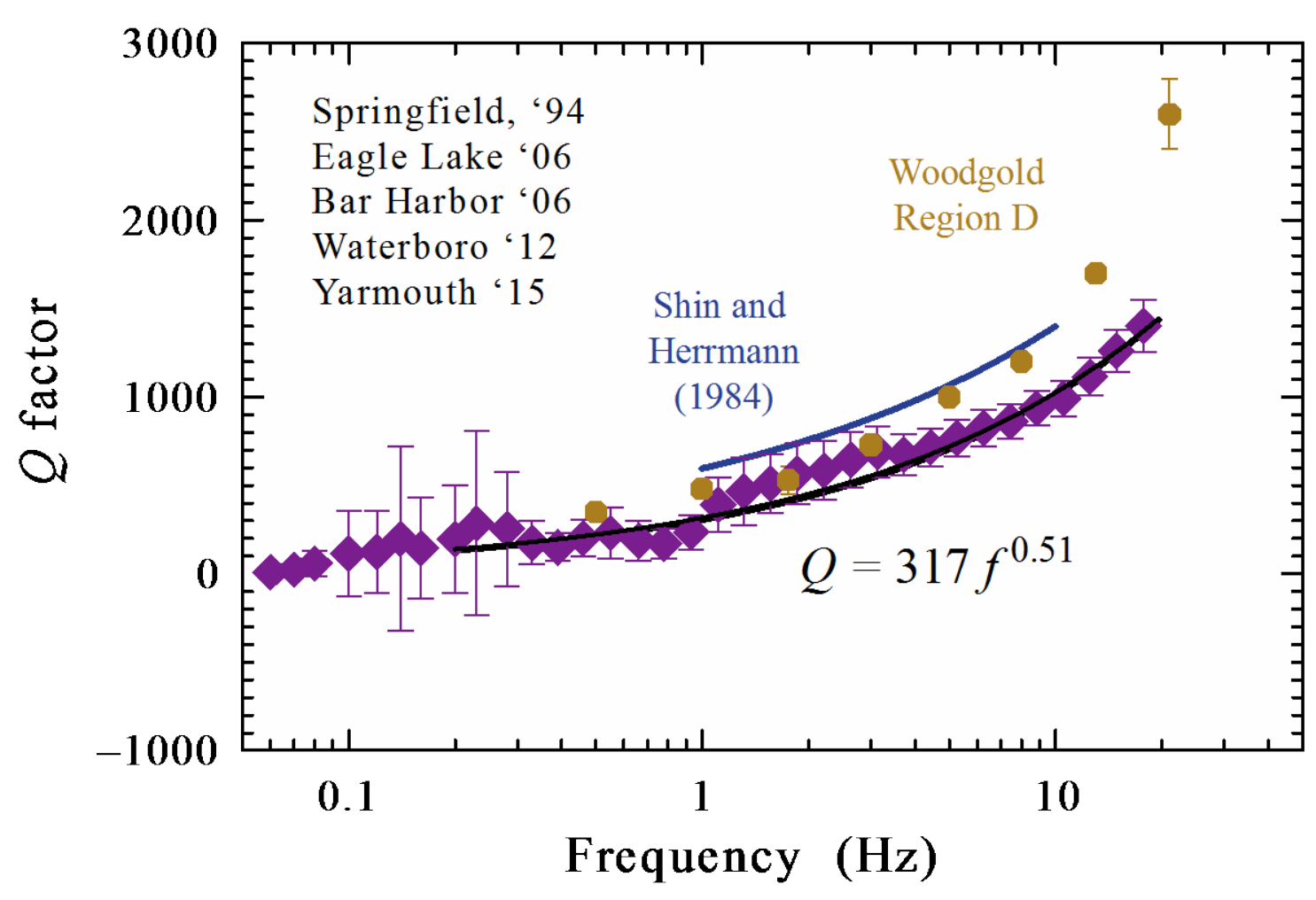

Figure 12. Graph of attenuation estimates from 5 earthquakes in Maine, fit from 0.2 to $20 \mathrm{~Hz}$. Q, attenuation; $\mathrm{Hz}$, cycles per second; $f$, frequency.

\section{Northern New York}

The northern New York region is relatively active. The Lamont Community Seismic Network (LCSN) has deployed short-period and broadband instruments in this region since the 1990s. We include four moderate earthquakes in the attenuation analysis, the raypaths are plotted in figure 13 . The earthquakes range in size, $M_{\mathrm{w}}$ 3.4-5.0, the 2002 Ausable Forks earthquake is the largest. Fitting the Aki and Chouet (1975) function from 0.2 to $20 \mathrm{~Hz}$ yields $Q=(359 \pm 46) f^{(0.54 \pm 0.05)}$. The relatively large uncertainties are the result of the small number of events analyzed. 


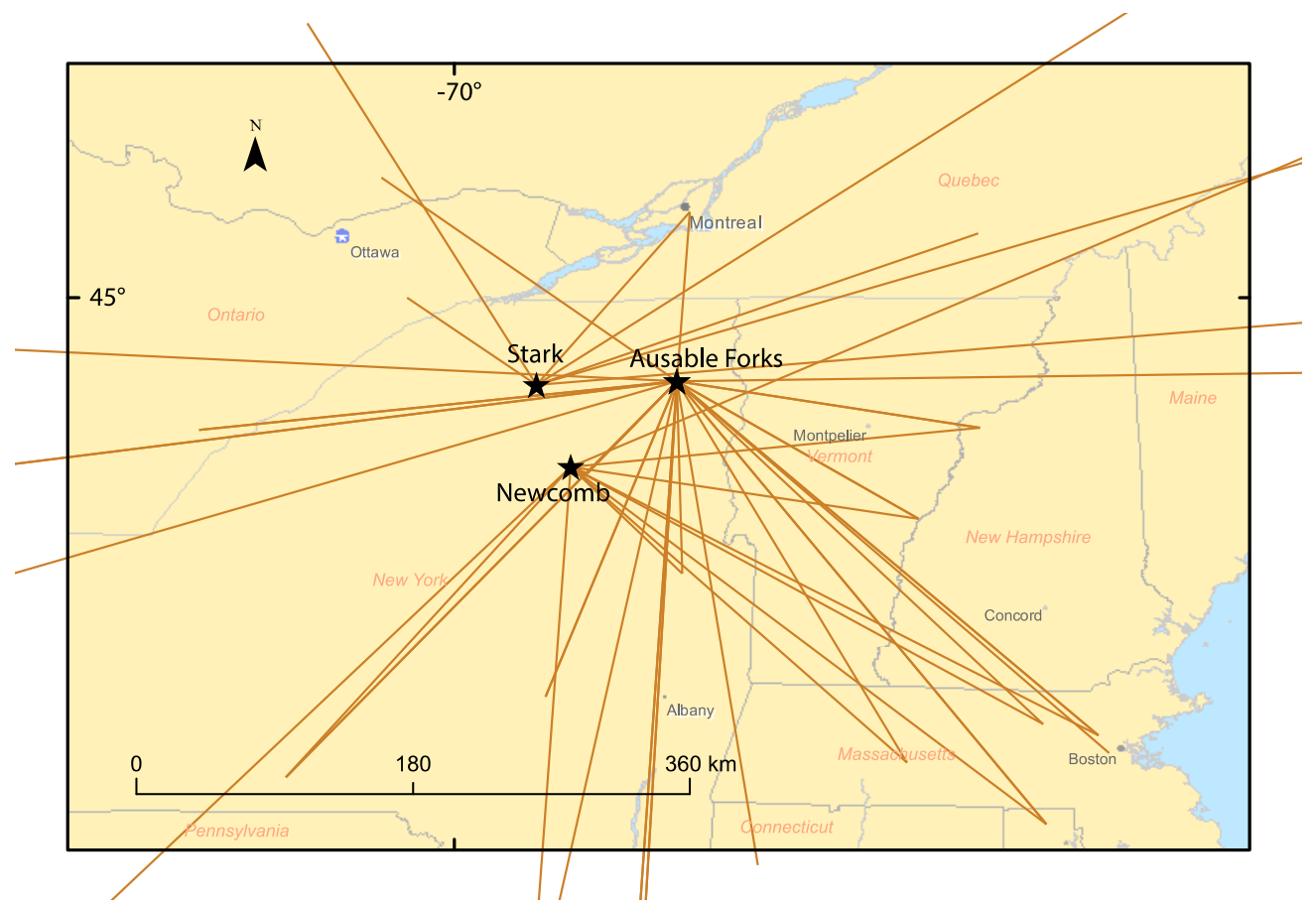

Figure 13. Map of raypaths from 4 earthquakes in New York.

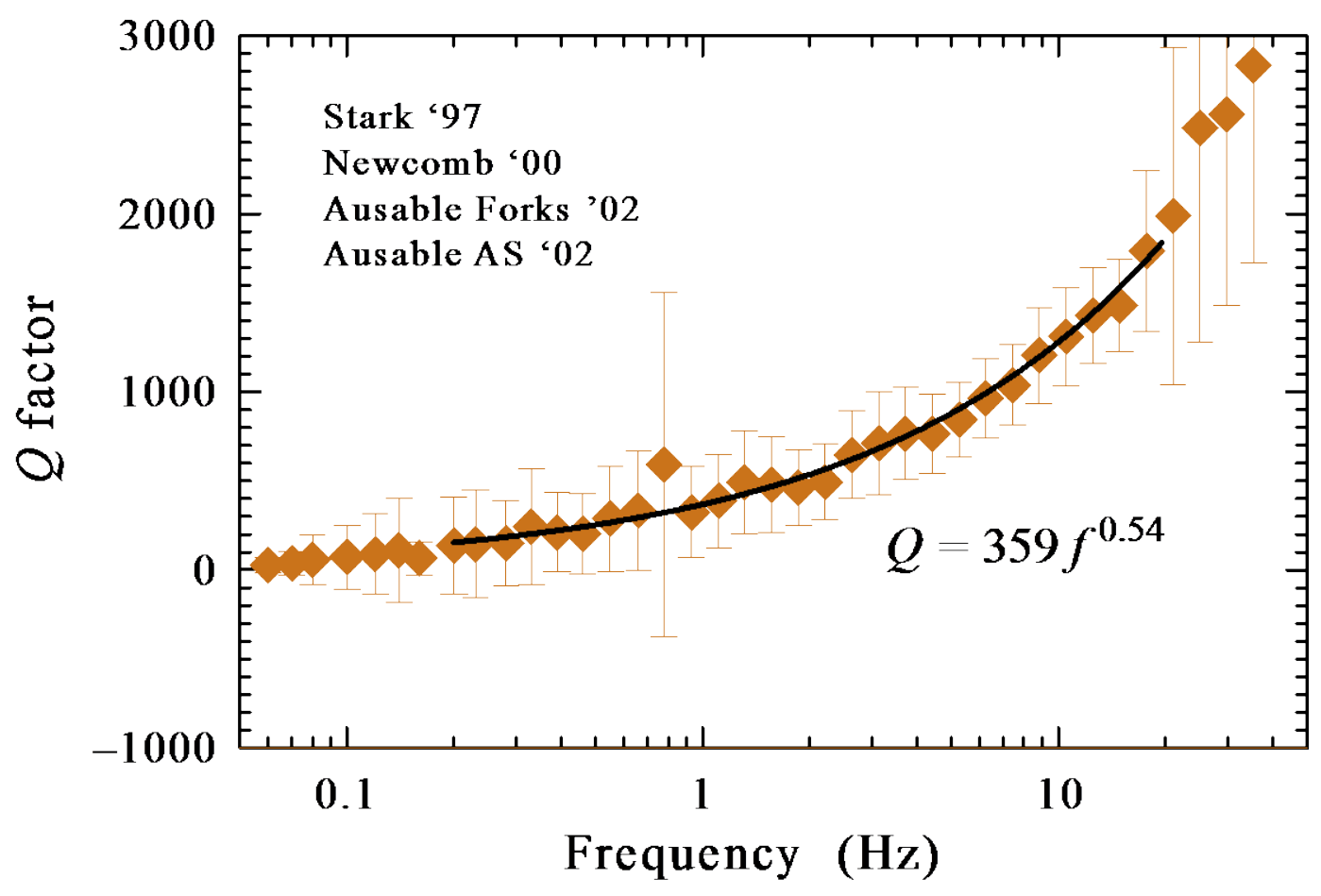

Figure 14. Graph of attenuation estimates from 4 earthquakes in New York. The fit is determined from 0.5 to 20 $\mathrm{Hz}$. Q, attenuation; Hz, cycles per second; $f$, frequency. 


\section{Lower Great Lakes}

The lower Great Lakes region encompasses the raypaths from three earthquakes in eastern Ohio and western Pennsylvania, and two earthquakes in southern Ontario. The raypaths for these five events are plotted in figure 15. Relatively few recent moderate earthquakes have occurred between northern New York and western Pennsylvania. The events range in size, $M_{\mathrm{w}}$ 3.0-4.6, the 1998 Pymatuning earthquake is the largest, and the 2004 Port Hope earthquake is the smallest.

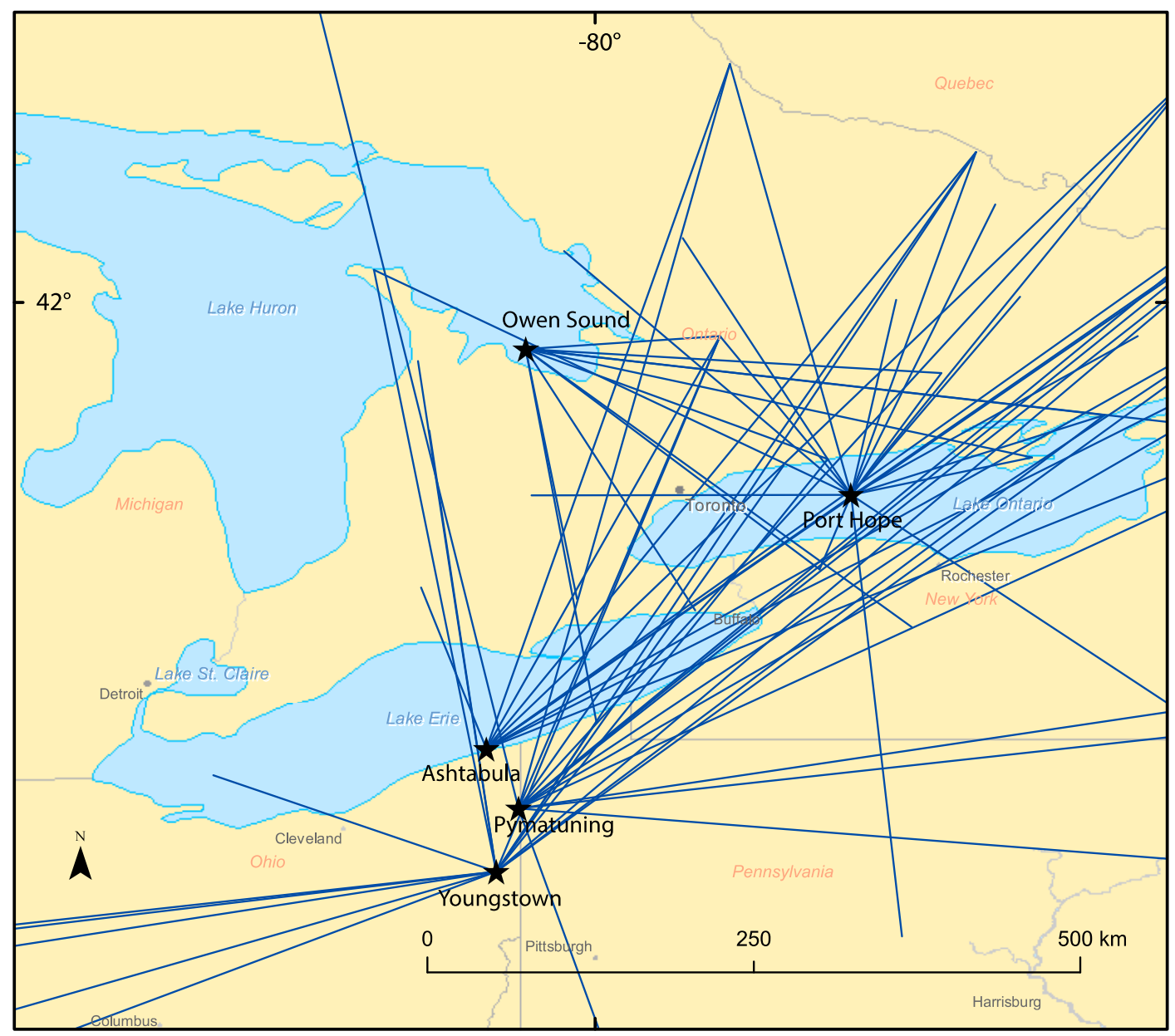

Figure 15. Map of raypaths for five earthquakes in Ohio, Pennsylvania, and Lake Ontario.

Fitting these estimates to the Aki and Chouet (1975) function from 0.5 to $20 \mathrm{~Hz}$ yields $Q=(331 \pm 30) f^{(0.61 \pm 0.04)}$. The attenuation estimates exhibit the strongest frequency dependence of any region studied. For this analysis, we adjust the low frequency limit for fitting the $Q_{0}$ f $\eta$ function from 0.2 to $0.5 \mathrm{~Hz}$ because these low estimates of attenuation distort the fit to the frequency band from 5 to 20 Hz. The fitted estimates agree with Woodgold's (1990) coda-Q estimates for the region. 


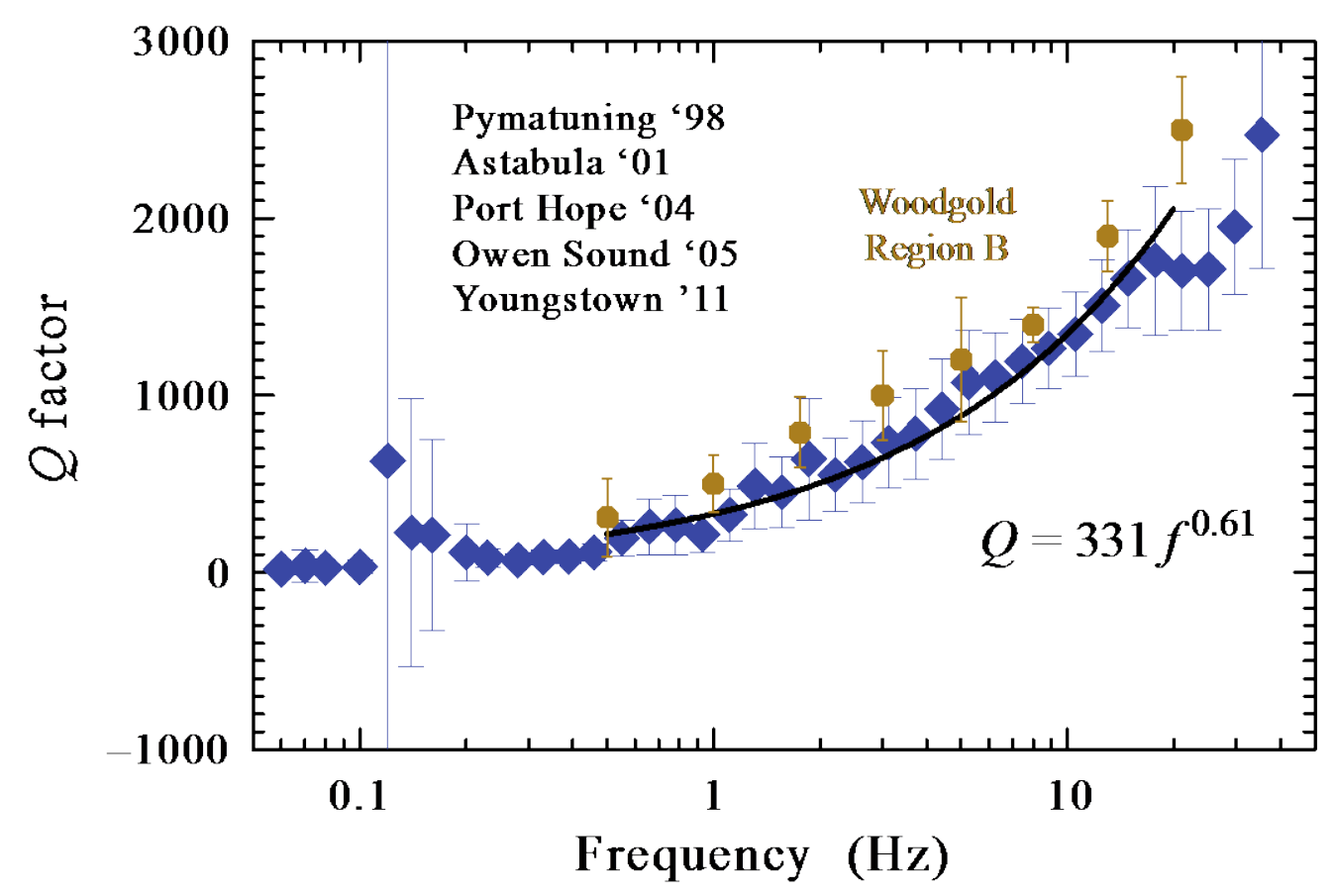

Figure 16. Graph of attenuation estimates from 5 earthquakes in Ohio, Pennsylvania, and southern Ontario. The fit is determined from 0.5 to $20 \mathrm{~Hz}$. Q, attenuation; $\mathrm{Hz}$, cycles per second; f, frequency.

\section{Ontario}

Ontario and western Quebec is the largest region analyzed. It includes the Grenville, Superior, and Churchill provinces of the Canadian Shield. The moderate earthquakes that have occurred there in the last 25 years provide excellent raypath coverage. We use 13 earthquakes to estimate the attenuation. The raypaths are plotted in figure 17. The events range in size, $M_{\mathrm{w}} 3.0-5.0$; the 2010 Val-des-Bois earthquake is the largest. We do not include stations to the southeast of events in the Western Quebec Seismic Zone, such as the Maniwaki and Val-des-Bois earthquakes.

Fitting these estimates to the Aki and Chouet (1975) function from 0.2 to $20 \mathrm{~Hz}$ yields $Q=(455 \pm 20) f^{(0.51 \pm 0.02)}$. The fit of the $Q_{o} f$ function to these attenuation estimates is not as good as the fits for the other regions: the fitted curve exceeds the estimates from 0.5 to $1.2 \mathrm{~Hz}$ and falls below them from 1.5 to $10 \mathrm{~Hz}$. The attenuation estimate is close to the Atkinson and Boore (2014) average, however most of the events that Atkinson and Boore (2014) analyze occurred in this region. 


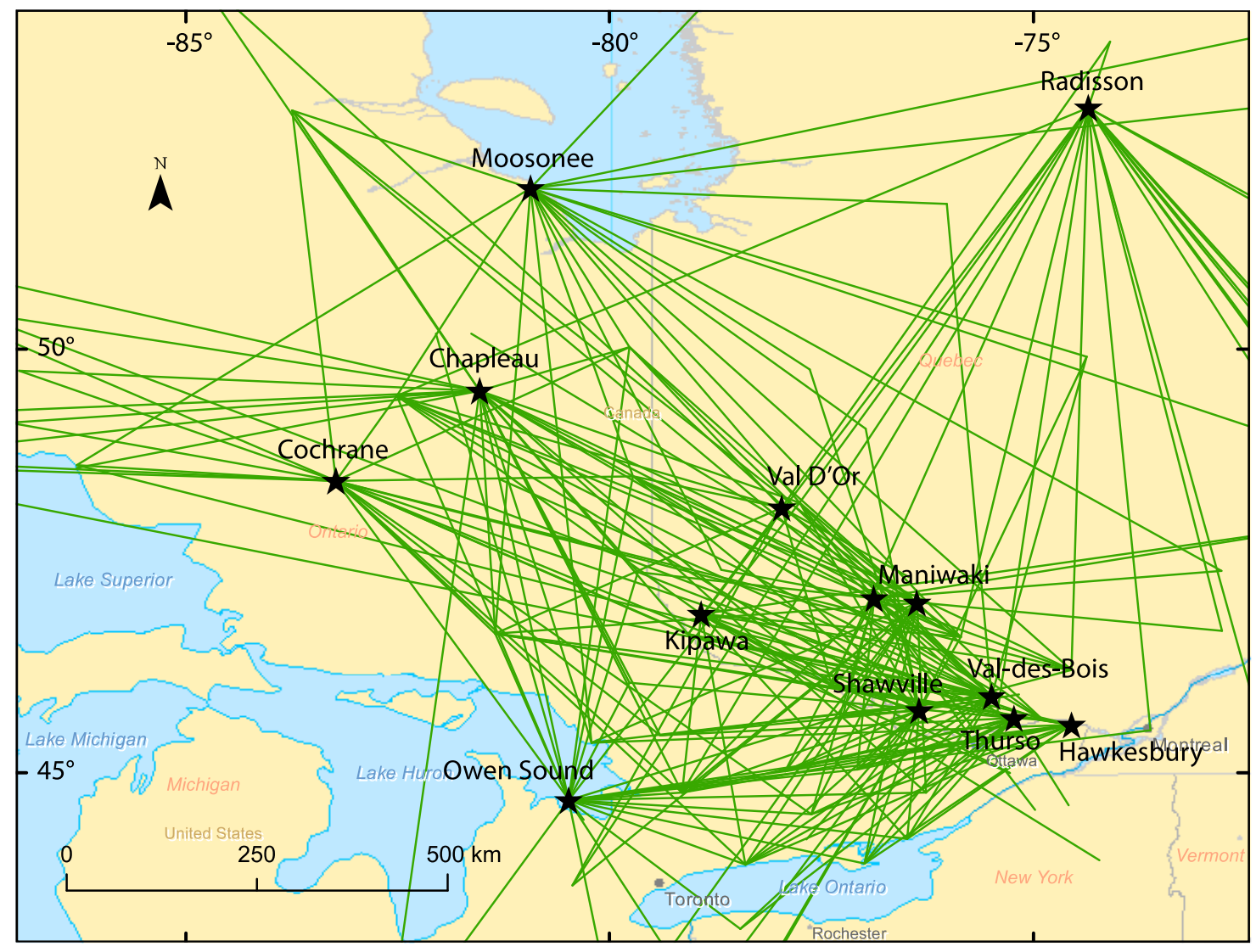

Figure 17. Map of raypaths for Ontario earthquakes. 


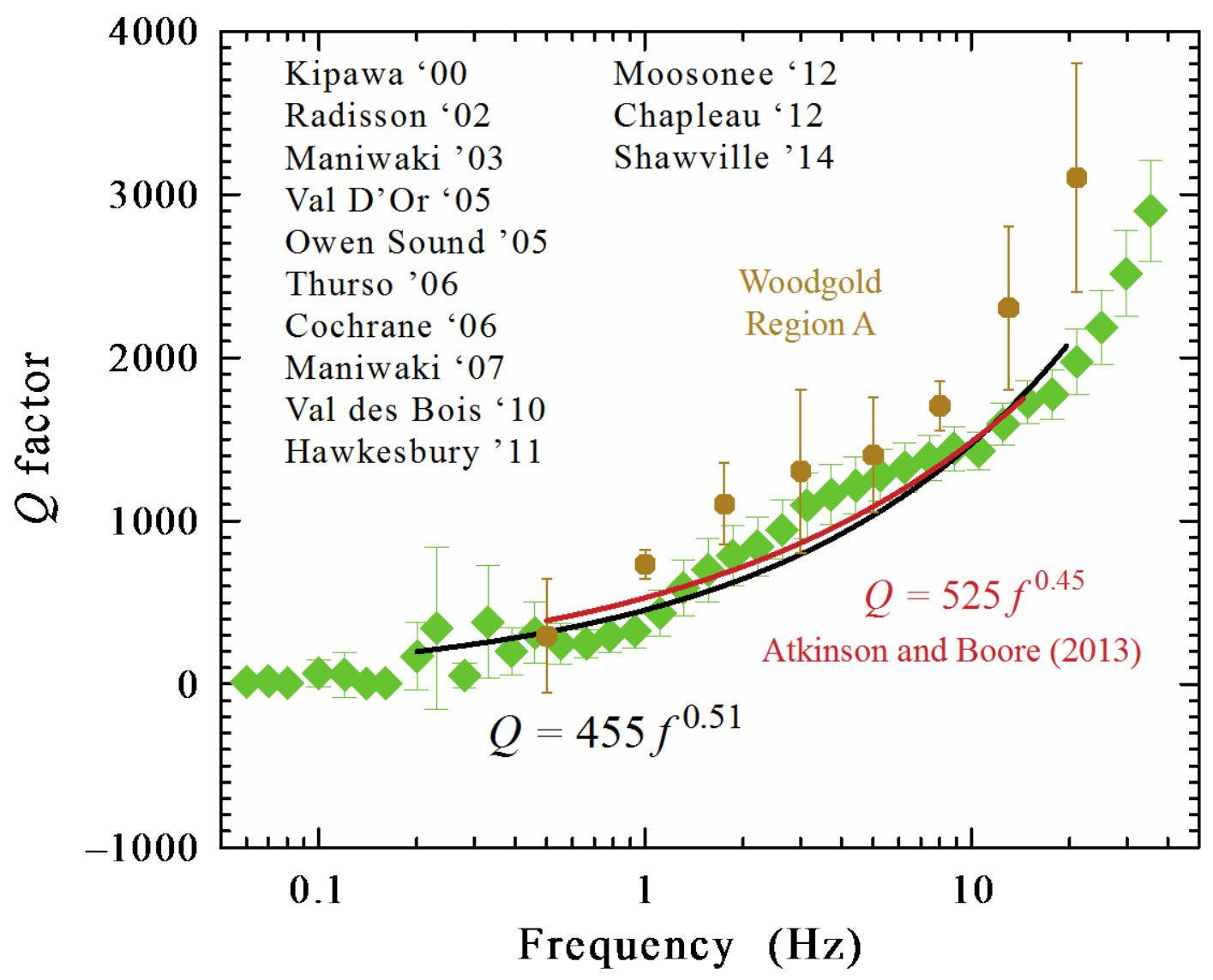

Figure 18. Graph of attenuation estimates for 10 earthquakes in Ontario and western Quebec, fit from 0.2 to 20 $\mathrm{Hz}$. Q, attenuation; $\mathrm{Hz}$, cycles per second; $f$, frequency.

\section{Nunavut}

The Nunavut region encompasses the raypaths from nine $M_{\mathrm{w}}$ 3.5-5.0 earthquakes located in northern Hudson Bay, shown in figure 19. The $1997 M_{\mathrm{w}}=5.0$ Nunavit earthquake is the largest. Five events were recorded by $4-10$ broadband stations deployed by the CNSN and POLARIS networks within $600 \mathrm{~km}$; eight were well recorded out to $1,000 \mathrm{~km}$, and the four largest events are well recorded out to $1,700 \mathrm{~km}$. 


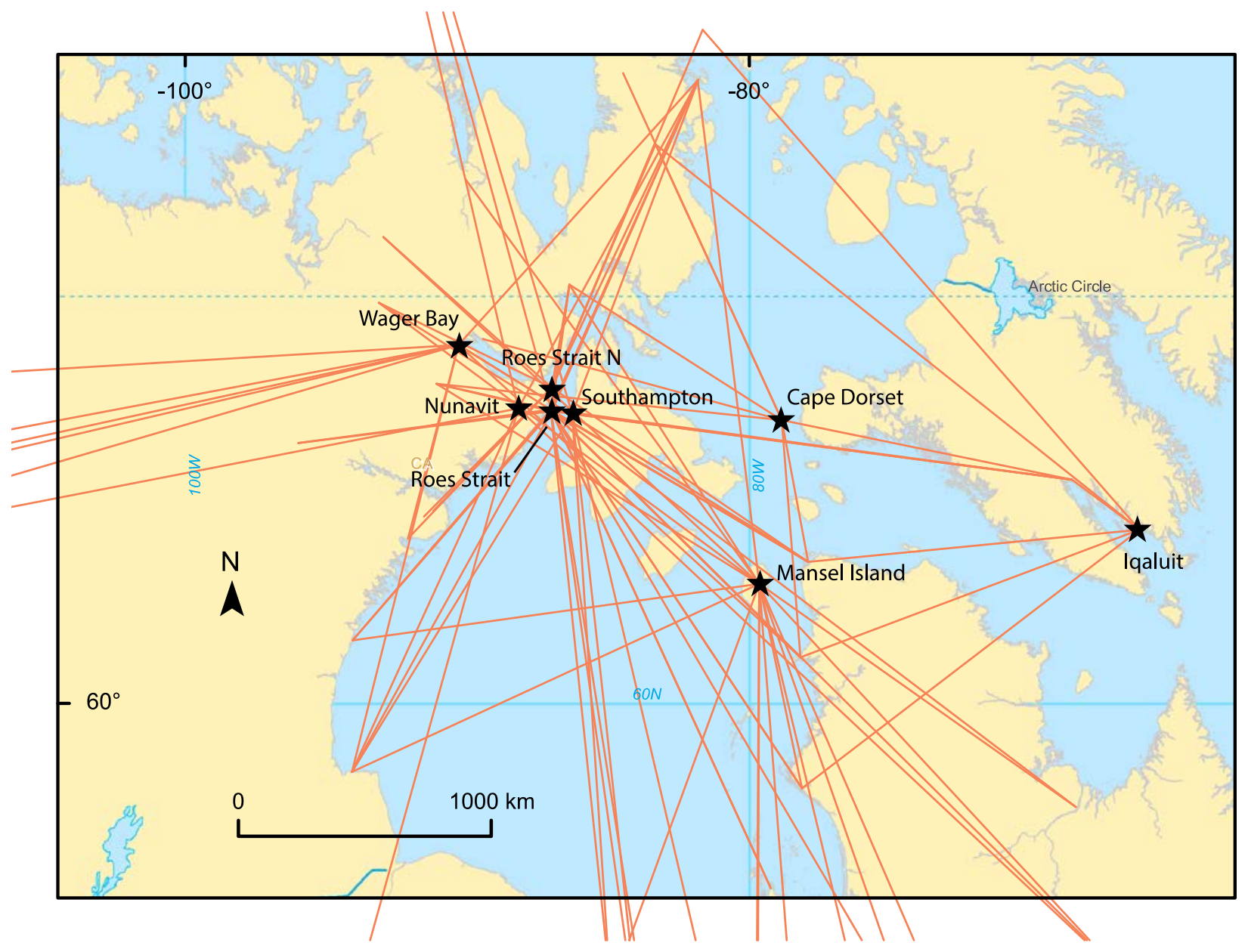

Figure 19. Map of ray-paths for northern Hudson Bay earthquakes.

We first estimate the average regional attenuation from the five events that were well recorded out to $600 \mathrm{~km}$, taking advantage of a POLARIS deployment of broadband instruments in Nunavut from 2007 to 2010. The attenuation estimates are shown in figure 20. Fitting these estimates to the Aki and Chouet (1975) function from 0.2 to $20 \mathrm{~Hz}$ gives $Q=(412 \pm 64) f^{(0.54 \pm 0.07)}$. While this estimate is not well resolved, it is close to the $L g$ attenuation estimated for Ontario and western Quebec. We assume that the result $Q=455 f^{0.51}$, drawn as a dashed line, is appropriate for Nunavut as well. 


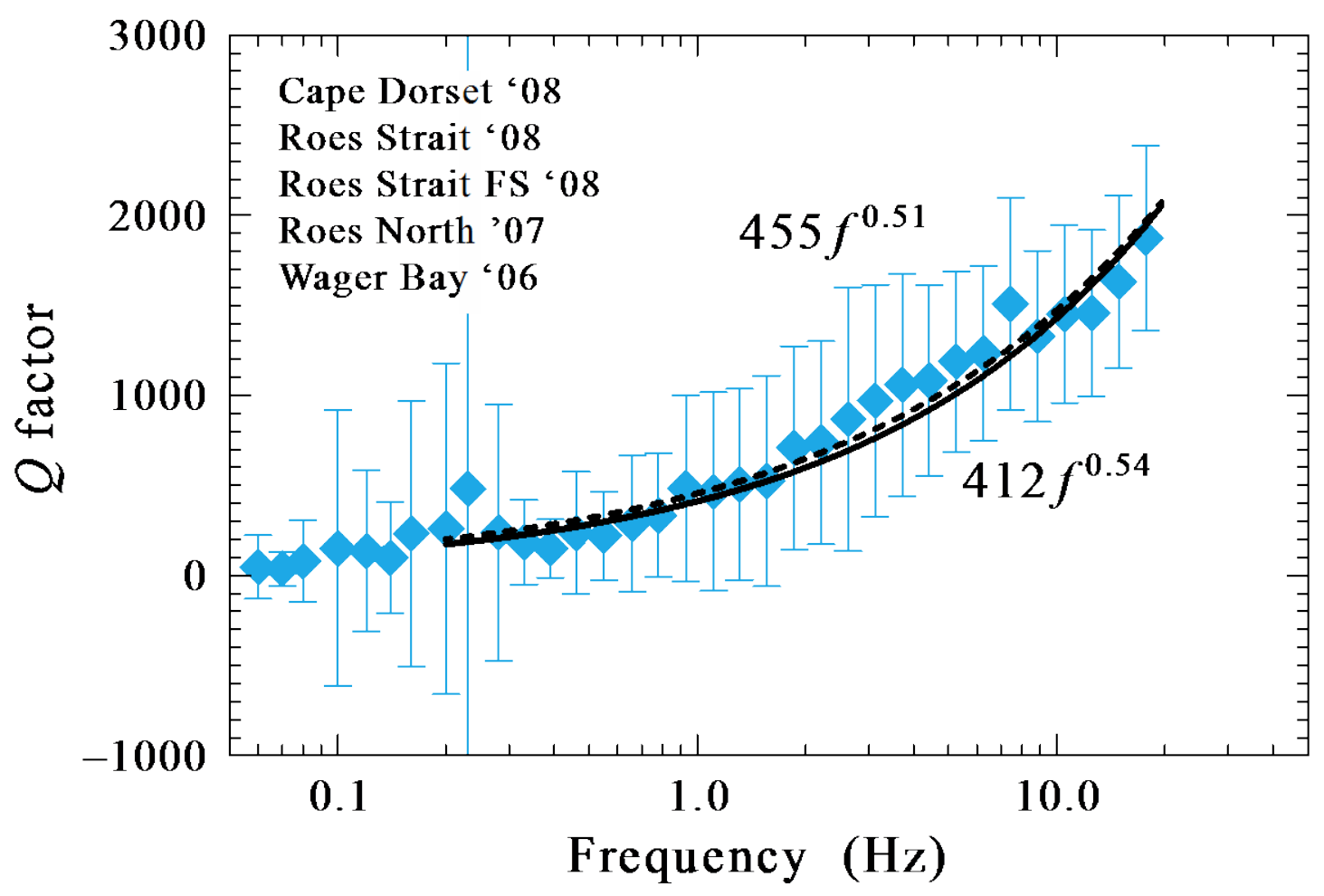

Figure 20. Graph of attenuation estimates for 5 events in Nunavut, fit from 0.2 to $20 \mathrm{~Hz}$. Q, attenuation; $\mathrm{Hz}$, cycles per second; $f$, frequency.

The microseismic noise in northern Canada is significantly less than the noise in southern Quebec and Ontario. This circumstance allows us to estimate $L g$ attenuation at greater distances. For this estimate, we use the $Q=455 f^{0.51}$ attenuation out to $450 \mathrm{~km}$ and invert for the $L g$ attenuation beyond $450 \mathrm{~km}$ using eight events that were recorded beyond $600 \mathrm{~km}$. We decrease the upper limit of the frequency band with distance to exclude noise, the spectra for the most distant stations are limited at 3 and $4 \mathrm{~Hz}$. Figure 21 shows these attenuation estimates plotted as a function of frequency. Fitting the Aki and Chouet (1975) function from 0.2 to $10 \mathrm{~Hz}$ yields $Q=(773 \pm 70) f^{(0.27 \pm 0.06)}$.

To test this result, we perform a similar inversion of spectra from 12 stations located 300 to $1,700 \mathrm{~km}$ northwest of the $2010 \mathrm{Val}$-des-Bois earthquake. That is, we assume that $L g$ attenuates as $Q=455 f^{0.51}$ out to $450 \mathrm{~km}$ and invert for the attenuation beyond $450 \mathrm{~km}$. These estimates are plotted as crosses without error bars, the uncertainties for these estimates are greater than the uncertainties for the Nunavut estimates. Fitting these two datasets together gives $Q=(729 \pm 70) f^{(0.31 \pm 0.06)}$. 


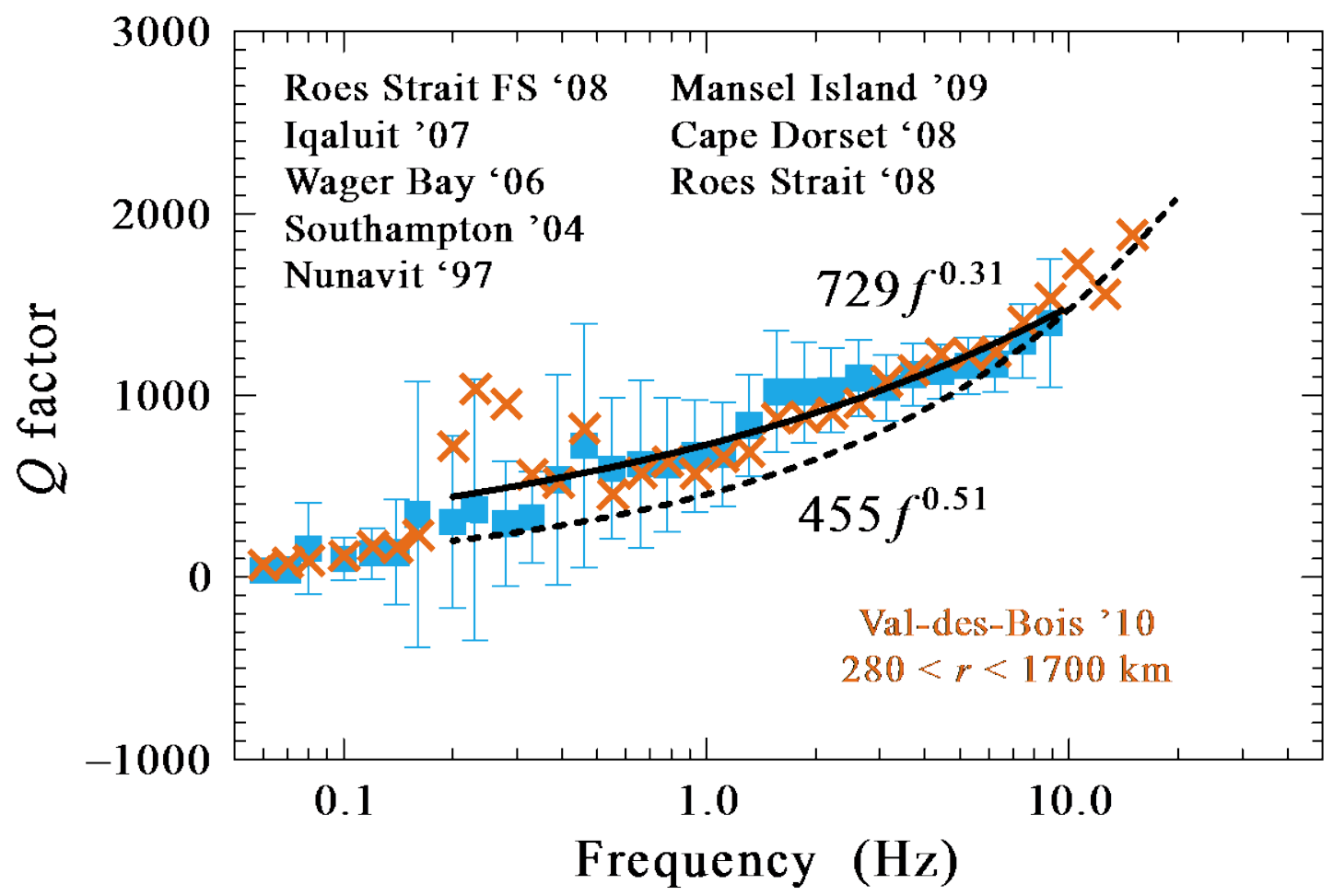

Figure 21. Graph of attenuation estimates from four earthquakes in Nunavut, fit from 0.2 to $15 \mathrm{~Hz}$, plotted as squares. The crosses show the attenuation estimates from an analysis of 11 stations at 300 to $1,700 \mathrm{~km}$ from the Val-des-Bois earthquake. Q, attenuation; $\mathrm{Hz}$, cycles per second; $f$, frequency.

The $L g$ attenuation over these far-regional distances is clearly different from the regional $L g$ attenuation. Specifically, the frequency dependence is reduced from $f^{0.5}$ to $f^{0.3}$. The regional and farregional attenuation coincide at $f \sim 10 \mathrm{~Hz}$, but the far-regional attenuation is less ( $Q$ is higher) at lower frequencies. This difference yields an important insight into the relation between $S n$ and $L g$. While they appear to be distinct phases, the change in $L g$ attenuation beyond $450 \mathrm{~km}$ implies that $S n$ scatters into $L g$ at these far-regional distances.

\section{Summary}

Analyzing the attenuation within these regions verifies our previous inference regarding $\mathrm{Lg}$ attenuation in northeastern North America, the attenuation in the Grenville province is different from the attenuation in the Appalachian province. The attenuation estimates in the Charlevoix, lower St. Lawrence, and Northern New York regions agree with an average of $Q=(368 \pm 13) f^{(0.54 \pm 0.02)}$. The attenuation in Maine is stronger ( $Q$ is lower) than the Appalachian average, while the attenuation in the lower Great Lakes decreases ( $Q$ increases) more rapidly with frequency.

The stronger attenuation in Maine shows that $L g$ attenuation increases in the lowlands east of the Appalachians, and suggests we can use these results to extend the attenuation in nearby regions. First, we assume the attenuation for Maine is also appropriate for southern New Hampshire and southeastern New England. Second, the comparisons with Woodgold's (1990) coda-Q results in figures C4 and C6 
indicate that the $\mathrm{Lg}$ attenuation in New Brunswick is intermediate between the lower St. Lawrence and Maine results; we assume $Q=350 f^{0.54}$ for New Brunswick.

The fits to Aki and Chouet's (1975) $Q_{o}$ f 7 function for these regions are striking. Six of the seven fitted curves fall entirely within the uncertainties of the attenuation estimates over two full decades of frequency. We assume this fidelity is characteristic of $L g$ attenuation, which occurs through scattering instead of absorption. The fit to the attenuation estimates in Ontario and western Quebec is not as close, this misfit may be the result of the physical extent of the region, which spans the Grenville, Superior, and Churchill provinces.

The attenuation analysis of the Nunavut earthquakes yields the unexpected result that $\mathrm{Lg}$ attenuation at distances beyond $450 \mathrm{~km}$ is less than the attenuation out to $450 \mathrm{~km}$, for frequencies below $10 \mathrm{~Hz}$. This variation with distance has not been observed previously. $\mathrm{Lg}$ studies that analyze data at farregional distances, such as Pasyanos (2013), assume that $L g$ attenuation is not inherently distance dependent. In the next section, we use this two-part attenuation model to estimate the source spectra for the $1989 M_{\mathrm{w}} 6.2$ Ungava and $M_{\mathrm{w}} 5.0$ Payne Bay earthquakes, which were recorded by CNSN stations in southern Quebec and Ontario at distances from 1,300 to 1,700 km.

\section{Earthquake Stress Drops in Northeastern North America}

Seismologists and engineers generally agree that stress drops of earthquakes in northeastern North America are greater than stress drops of earthquakes in the western United States. This consensus was strengthened by Boore and Atkinson's (1992) estimate of a 500 bar stress drop for the $M_{\mathrm{w}} 5.81988$ Saguenay earthquake. Boatwright and Seekins (2011) and Boore (2012) subsequently demonstrated that moderate-sized (4.3< $\left.M_{\mathrm{w}}<4.7\right)$ earthquakes in Quebec also exhibit large stress drops (200-350 bars) although smaller than that of the Saguenay earthquake.

The variation of NENA stress drops with moment magnitude, source depth, and source region is not well determined. Yet these variations are critical for predicting strong ground motion from future large earthquakes. In this section, we consider the variation of stress drop with moment magnitude and depth $(h)$; that is, we regress the stress drops of these earthquakes against $M_{\mathrm{w}}$ and $\log (h)$ as:

$$
\log (\Lambda \sigma)=\log \left(\Lambda \sigma_{\mathrm{o}}\right)+\xi \mathrm{M}_{\mathrm{w}}+\zeta \log (h)
$$

for earthquakes in different regions. The seismic moments, acceleration spectral levels, and corner frequencies are estimated following Boatwright and Seekins (2011), but we modify their estimate of the variance of the acceleration spectral level. Boatwright and Seekins (2011) underestimated this variance: their analysis assumed that the corner frequency was known beforehand.

This section follows the structure of the previous section, where we determined the $\mathrm{S}+\mathrm{Lg}$ attenuation in seven regions, but here we aggregate the earthquakes into three larger regions: Charlevoix and the lower St. Lawrence; Ontario, western Quebec, Nunavut, and the Ungava Peninsula; and New England, Pennsylvania, Virginia, Ohio, and Michigan. These groupings are predicated on the similarity of the earthquake stress drops and the attenuation in these regions. In addition, the range of earthquake magnitudes and source depths in each of these regions has to be sufficient to resolve the dependence of the stress drop on these parameters.

\section{Charlevoix and the lower St. Lawrence}

We group these two regions together because they are situated between the same geologic provinces, the Appalachian and Grenville provinces, and they have similar attenuation and a similar range of source depths. The 51 earthquakes range in size from $M_{\mathrm{w}} 2.2$ to the $M_{\mathrm{w}} 5.8$ Saguenay 
earthquake. Their locations are plotted in figure 22, together with the locations of earthquakes in New Brunswick and New England.

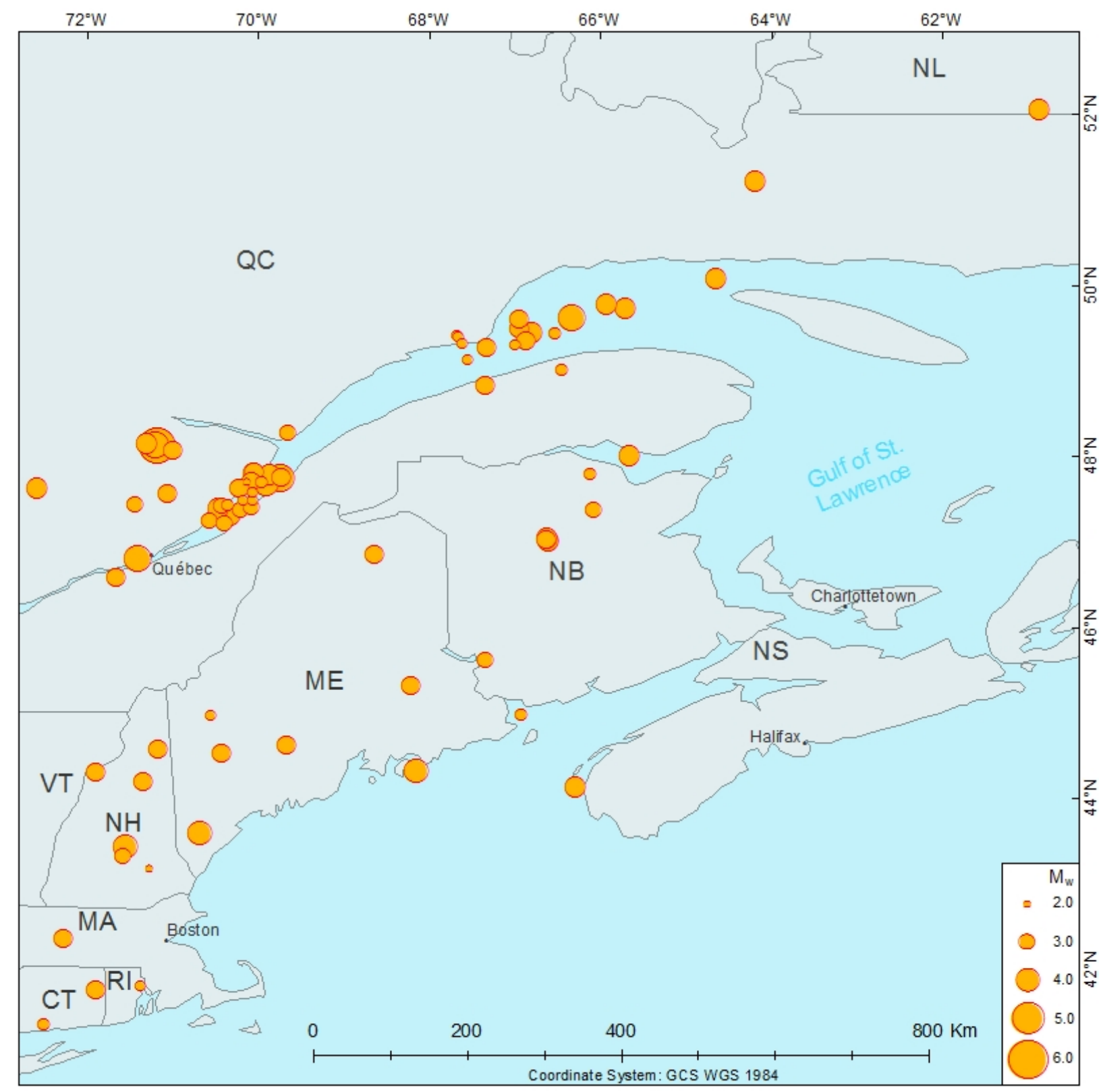

Figure 22. Map of epicenters of earthquakes in Charlevoix, the Lower St. Lawrence, New Brunswick, and New England. Symbol size scales with moment magnitude $\left(M_{\mathrm{w}}\right)$.

Figure 23 shows the earthquake stress drops for Charlevoix, lower St. Lawrence, and New Brunswick, plotted against moment magnitude. This plot demonstrates the problem that the Saguenay earthquake poses for earthquake engineers. Because it is the largest earthquake in this region and has such a large stress drop, it strongly conditions estimates of ground motions for future large earthquakes in NENA. 


\section{Stress Drop vs Magnitude}

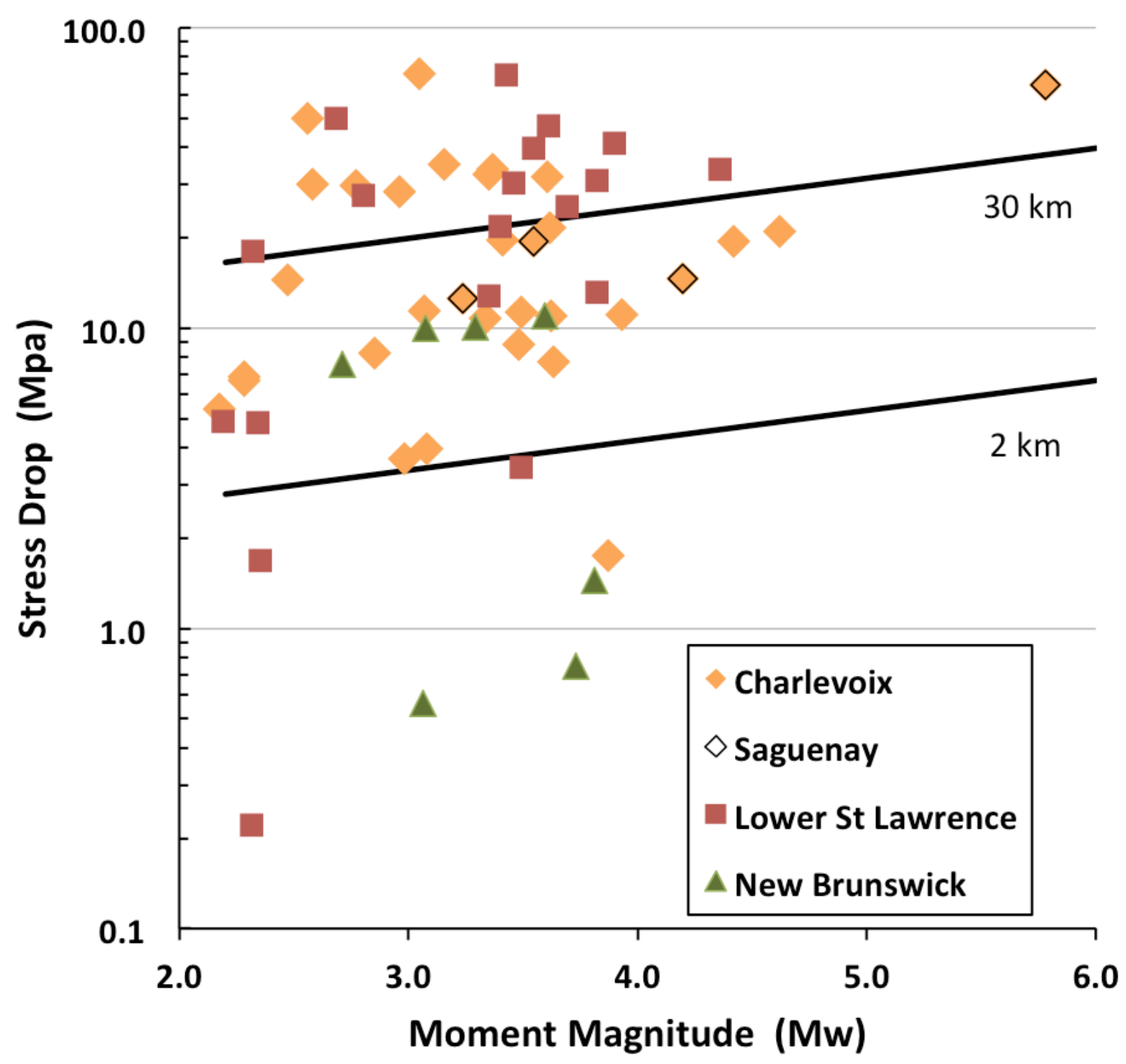

Figure 23. Graph of stress drop plotted against moment magnitude $\left(M_{w}\right)$ for Charlevoix, lower St. Lawrence, and New Brunswick earthquakes. The symbols for the foreshock, main shock, and two aftershocks of the Saguenay sequence are outlined. The dark lines show the result of the regression in equation 5. Mpa, megapascal; $\mathrm{km}$, kilometer.

The Saguenay earthquake appears less anomalous when stress drop is plotted against source depth in figure 24 , other deep earthquakes $(15<h<30 \mathrm{~km})$ have similarly large stress drops. The increase of stress drop with depth for these earthquakes is clear, despite the lack of shallow earthquakes. 


\section{Stress Drop vs Depth}

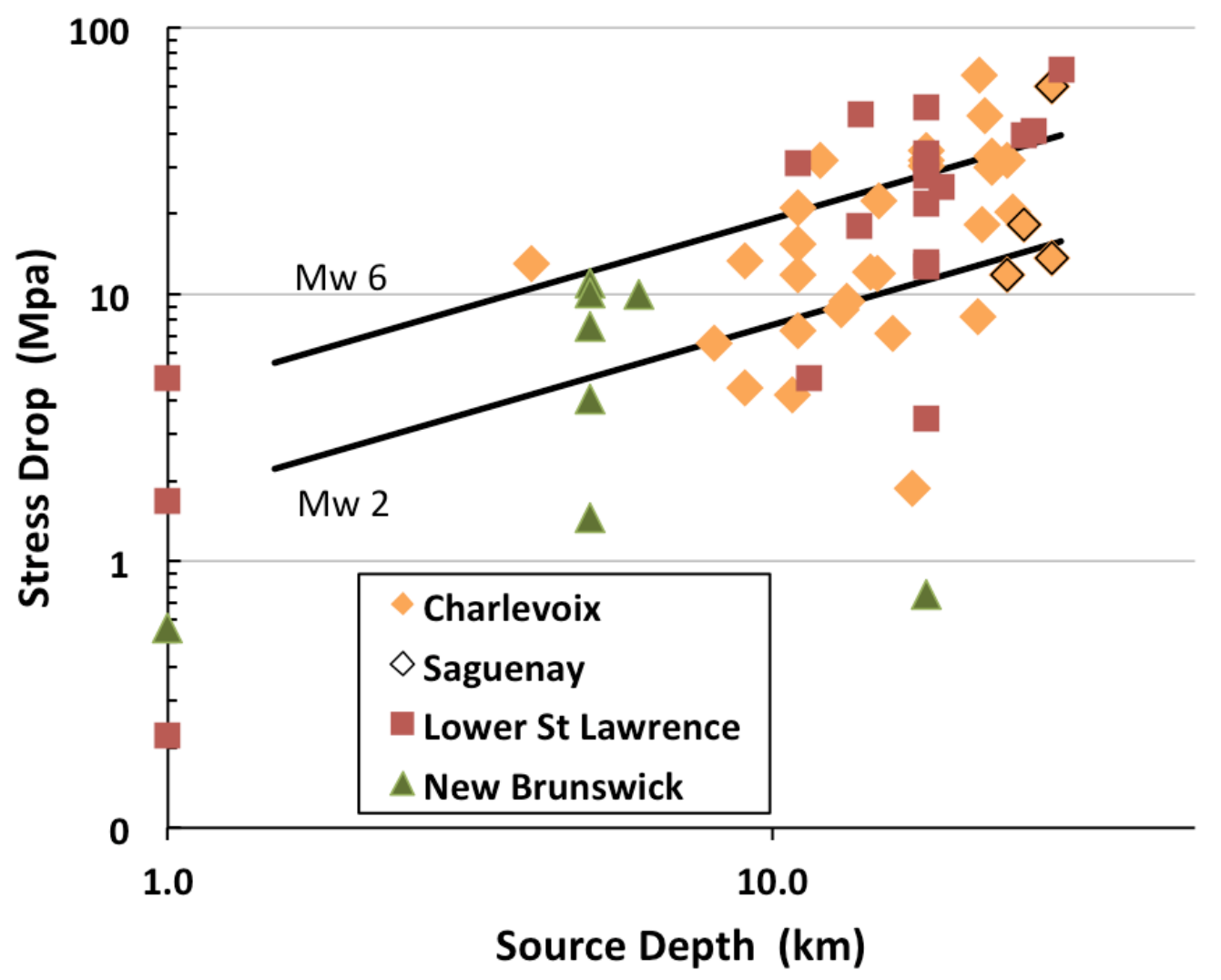

Figure 24. Graph of stress drop plotted against source depth for Charlevoix, lower St. Lawrence, and New Brunswick earthquakes. The dark lines show the result of the regression in equation 5. $M_{w}$, moment magnitude; Mpa, megapascal, km; kilometer.

The uncertainties of the source depths vary markedly, the depths of the Charlevoix earthquakes are well determined, owing to the six broadband stations installed by the CNSN) in 1987, while the depths of the earthquakes beneath the St. Lawrence Seaway are poorly constrained. The three small shallow $\left(M_{\mathrm{w}} \sim 2.3, h \sim 1 \mathrm{~km}\right)$ earthquakes in Baie Comeau occurred near enough to CNSN station CNQ that their hypocentral depths are adequately constrained.

The lines showing the variation of stress drop with magnitude in figure 23 and with depth in figure 24 were obtained by regressing the stress drops of the Charlevoix and lower St. Lawrence in equation 5 . These two sets of lines are parallel because there is no mixed $\left(M_{\mathrm{w}} \log (h)\right)$ term in the regression. The stress drops for the eight New Brunswick earthquakes were not included in the regression as they appear to be significantly lower.

\section{Ontario, western Quebec, New York State, and Nunavut}

We group these regions together because of their similar attenuation and broadly distributed seismicity. The locations of the Ontario and western Quebec earthquakes are plotted in figure 25. These 38 earthquakes range in size from $M_{\mathrm{w}} 2.4$ to the $M_{\mathrm{w}} 5.0$ Val de Bois earthquake. The cluster of earthquakes to the northwest of Ottawa marks the Western Quebec Seismic Zone (WQSZ). We include the New York State earthquakes in this set because of their proximity to the WQSZ. 


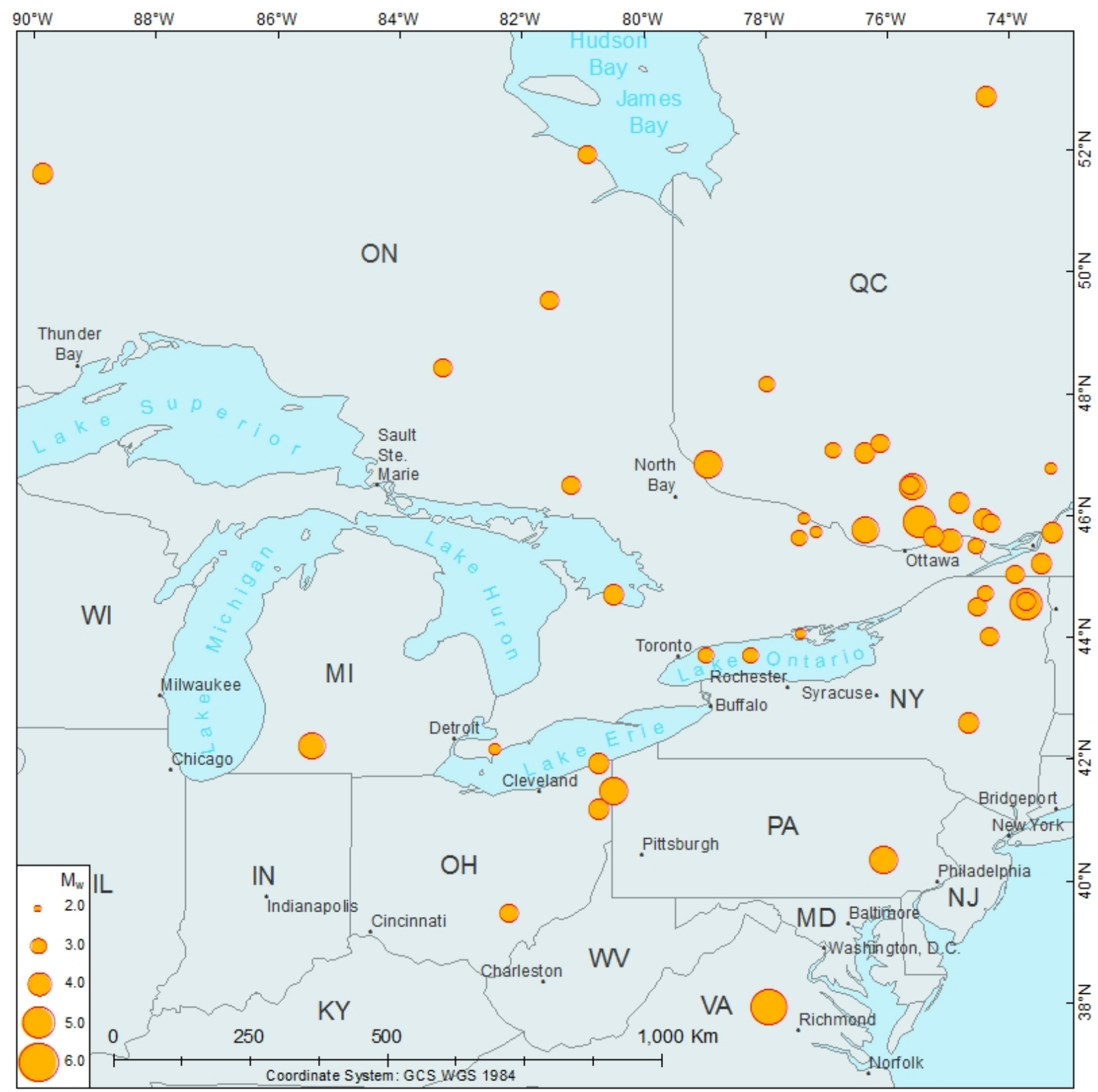

Figure 25. Map of epicenters of earthquakes in Ontario, western Quebec, and central and eastern United States. Symbol size scales with moment magnitude $\left(M_{\mathrm{w}}\right)$. $\mathrm{km}$, kilometer.

The locations of the Nunavut and northern Quebec earthquakes are plotted in figure 26. The 16 earthquakes in this region range in size from $\mathrm{Mw} 3.5$ to the Mw 6.1 Ungava earthquake; no smaller earthquakes were analyzed because the stations in this region are almost all sampled at $40 \mathrm{~Hz}$ and the available frequency band is insufficient to estimate corner frequency for smaller earthquakes. Four of these earthquakes occurred in the Ungava Peninsula and eight occurred in or near Roes Strait, the body of water that separates Southampton Island from Nunavut. 


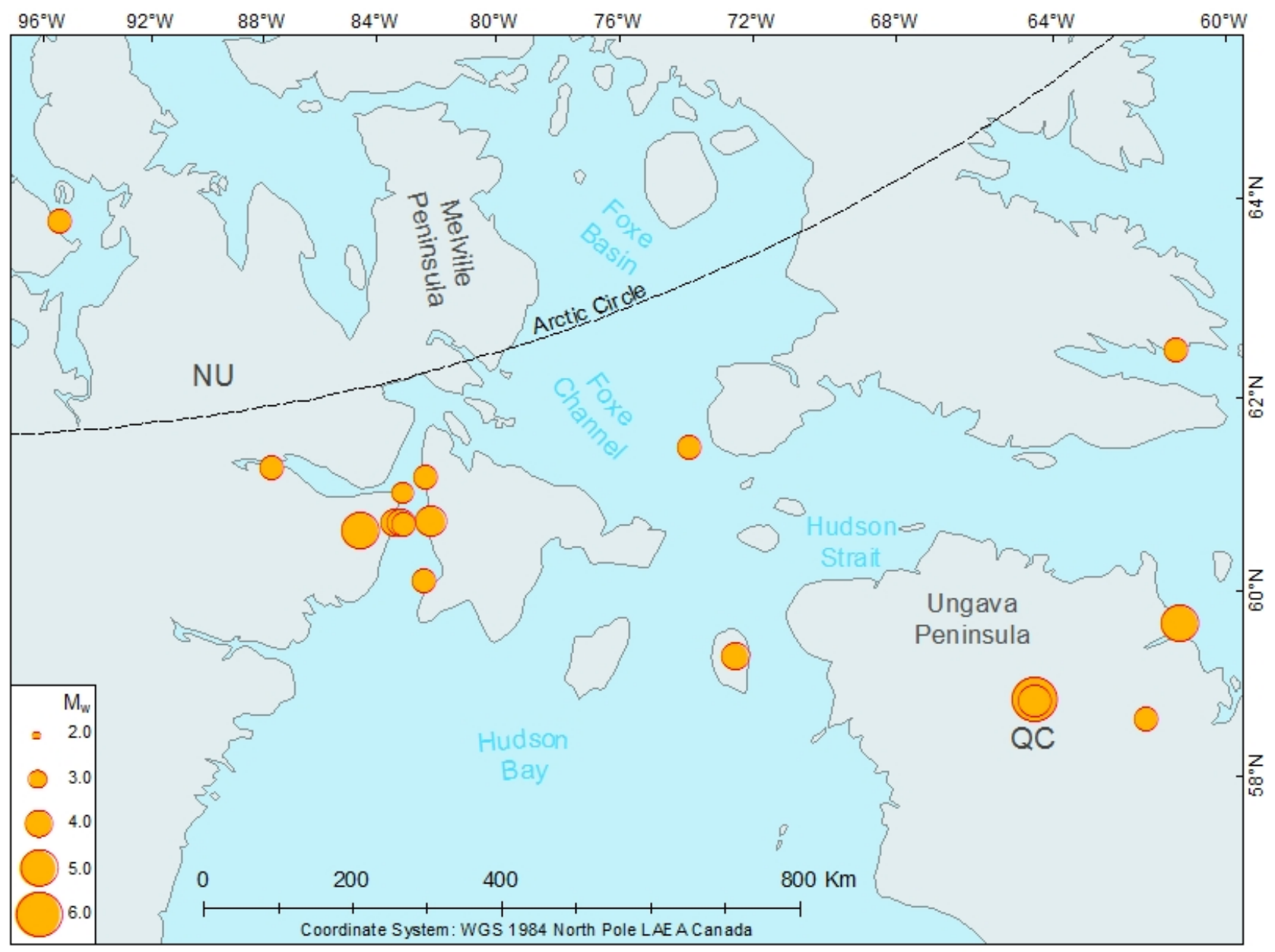

Figure 26. Map of epicenters of earthquakes in Nunavut and northern Quebec that were analyzed. Symbol size scales with moment magnitude $\left(M_{\mathrm{w}}\right) . \mathrm{km}$, kilometer.

Figure 27 shows the earthquake stress drops plotted against moment magnitude, adding the Nunavut events doubles the number of Mw >4 earthquakes. The Mw 6.11989 Ungava earthquake was the largest earthquake to occur in this region, the 118 bar stress drop for this earthquake is substantially less than the 644 bar stress drop for the Saguenay earthquake, possibly because of the difference in source depth. 


\section{Stress Drop vs Moment Magnitude}

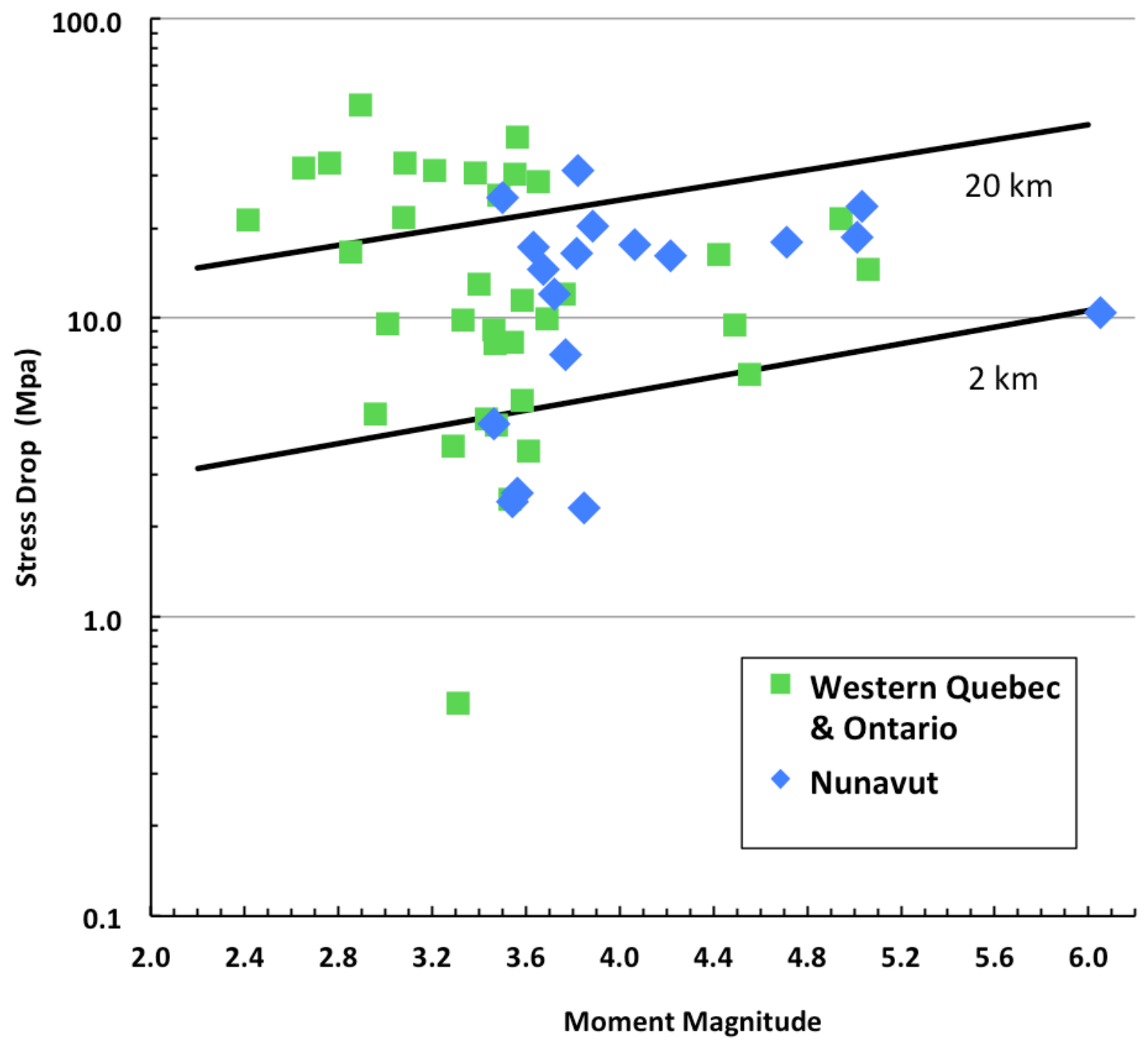

Figure 27. Graph of stress drop plotted against moment magnitude for the Ontario, western Quebec, New York, and Nunavut earthquakes. Mpa, megapascal; km, kilometer.

Figure 28 shows the earthquake stress drops plotted against source depth. Overall, the stress drops for the Ontario, western Quebec, New York State, and Nunavut earthquakes are similar to the stress drops for the Charlevoix and lower St. Lawrence earthquakes. The variation of stress drop with both magnitude and source depth for these earthquakes appears slightly stronger than the variation for the Charlevoix and lower St. Lawrence earthquakes. No events in the Ontario or Nunavut event set are smaller than $M_{\mathrm{w}}=2.4$ or deeper than $23 \mathrm{~km}$. 


\section{Stress Drop vs Depth}

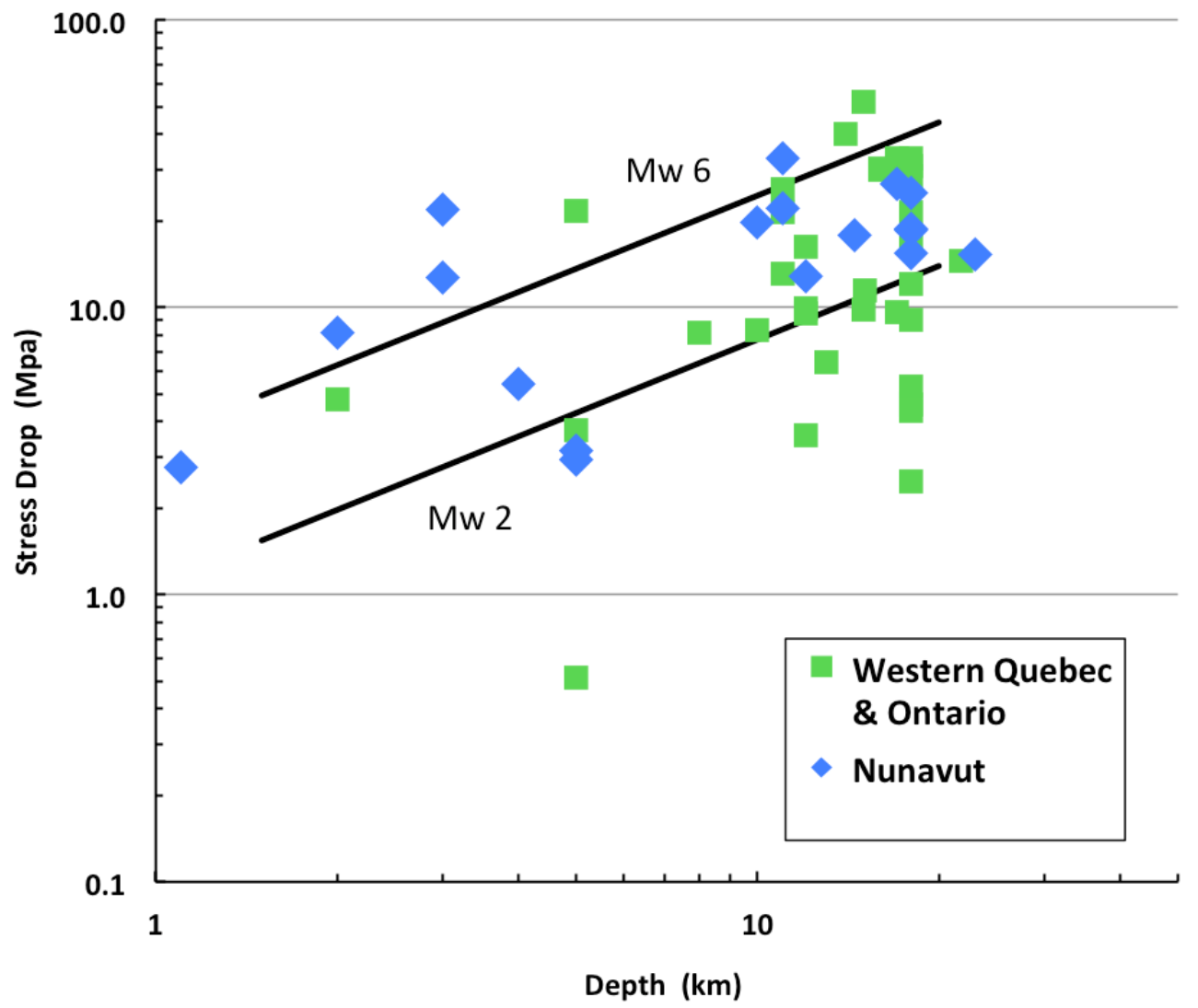

Figure 28. Graph of stress drop plotted against source depth for Ontario, western Quebec, New York, and Nunavut earthquakes. Mpa; megapascal; km, kilometer.

\section{New England, Pennsylvania, Virginia, Ohio, and Michigan}

These regions are grouped together in part because they constitute a United States event set and in part because their stress drops appear similar. (The earthquakes in northern New York State are included in the Ontario and Western Quebec set.) The 32 earthquakes range in size from $M_{\mathrm{w}} 2.0$ to 5.7: the largest is the $M_{\mathrm{w}} 5.7$ Mineral, Va., earthquake. The locations of these earthquakes are plotted on figures 24 and 25.

Almost no small $\left(M_{\mathrm{w}}<3\right)$ earthquakes in the central United States were analyzed. This absence of small earthquakes is because of the lack of broadband stations in this region before 2010 and to the low (40 samples per second) sampling rate of the Transportable Array stations in this region. The limited frequency band $(f<20 \mathrm{~Hz})$ precludes estimating corner frequency and stress drop for small earthquakes.

Figures 29 and 30 show the earthquake stress drops plotted against moment magnitude and source depth, respectively. Including the $M_{\mathrm{w}} 5.8$ Mineral earthquake yields an interesting symmetry between the three earthquake sets, where the largest earthquake in each set is more than a magnitude unit larger than the second largest. For the eastern Quebec and United States sets, the largest earthquake has the largest stress drop. For the Ontario and Nunavut set, the largest earthquake has a relatively low stress drop. 


\section{Stress Drop vs Moment Magnitude}

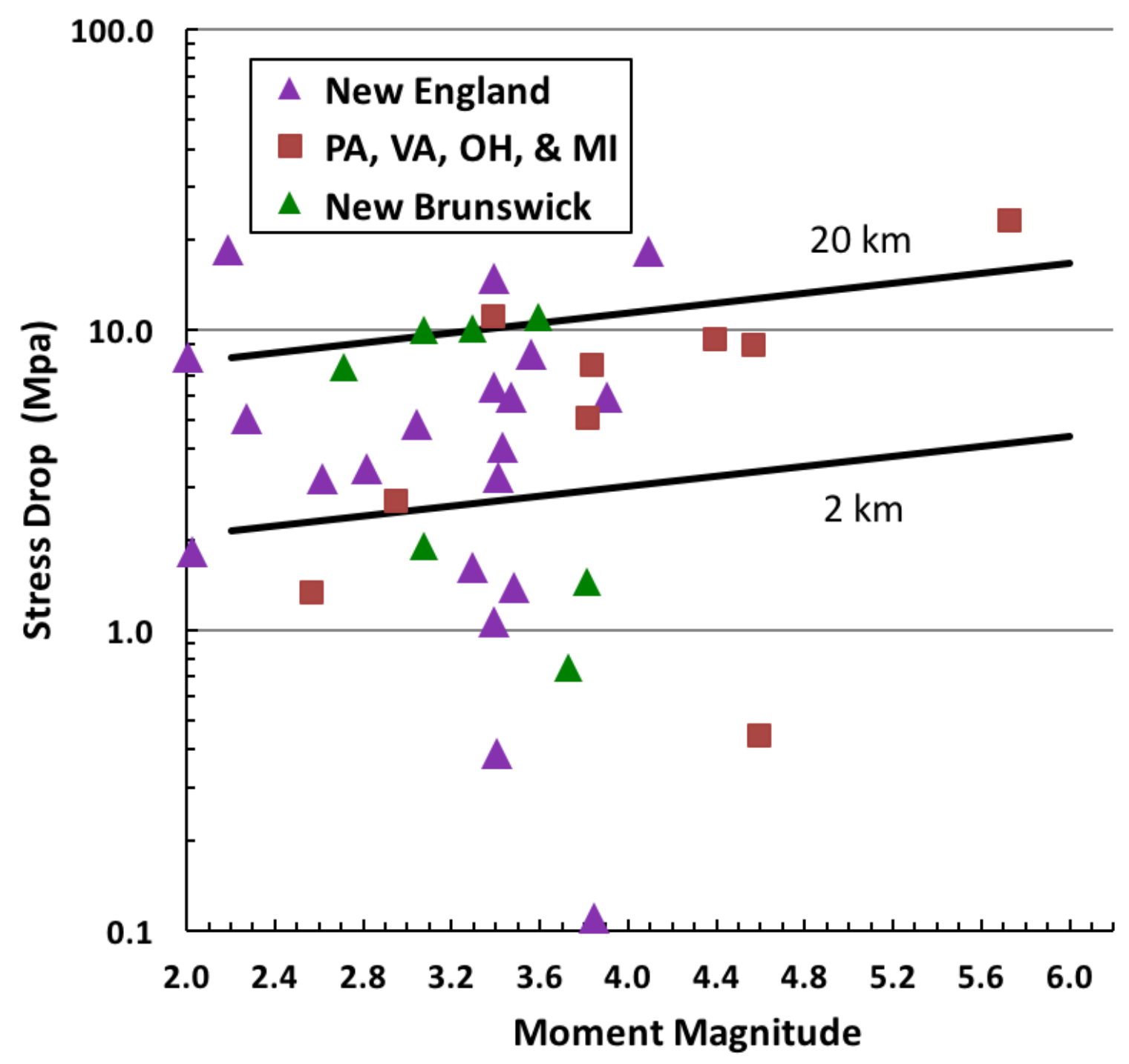

Figure 29. Graph of stress drop plotted against moment magnitude for New England, Pennsylvania, Virginia, Ohio, and Michigan earthquakes. The New Brunswick earthquakes are plotted to compare the average stress drop for these regions, but were not included in the regression. Mpa, megapascal; km, kilometer. 


\section{Stress Drop vs Depth}

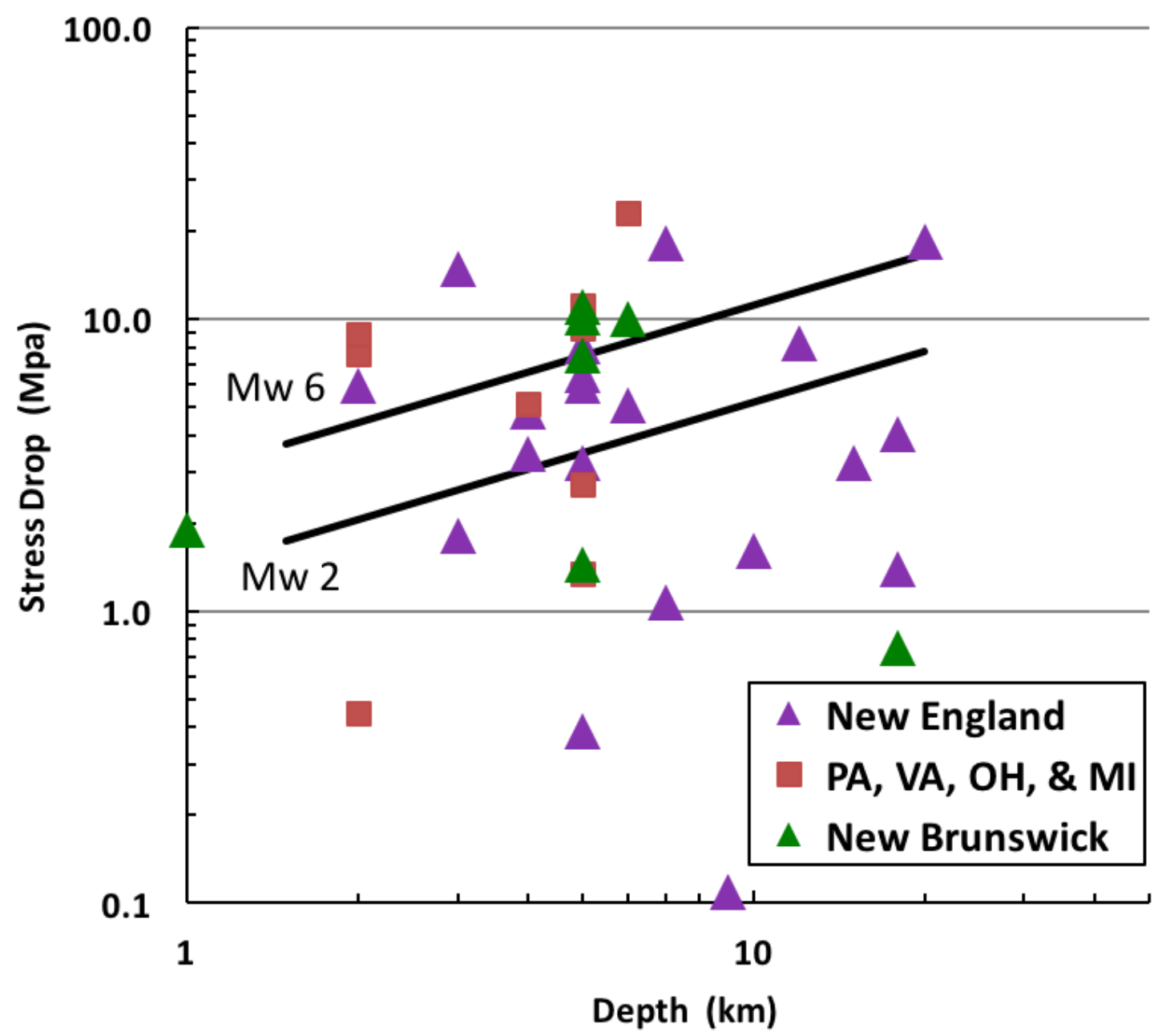

Figure 30. Graph of stress drop plotted against source depth for New England, Pennsylvania, Virginia, Ohio, and Michigan earthquakes. The New Brunswick earthquakes are not included in the regression. Mpa, megapascal; $\mathrm{km}$, kilometer; $M_{\mathrm{w}}$, moment magnitude.

The stress drops of the New Brunswick earthquakes are plotted on both figures, although they are not included in the regression. These eight events illustrate the difficulty of regionalizing earthquakes to predict ground motion. They are relatively small, $M_{\mathrm{w}}<4$, and have relatively low stress drops. Their stress drops are similar to the stress drops of the New England earthquakes, but clearly less than the stress drops of the Charlevoix and lower St. Lawrence earthquakes. There are too few New Brunswick events to reliably extrapolate these results to $M_{\mathrm{w}}>6$ earthquakes. Thus ground motion predictions for New Brunswick depend explicitly on how the earthquakes are regionalized.

Summary

This set of 144 events contains $21 M_{\mathrm{w}}>4$ earthquakes, nine of which have not been previously analyzed. The estimates of moment magnitude, seismic moment, radiated energy, and stress drop obtained for the 21 earthquakes are presented in table 2 below. The 1988 Saguenay earthquake has the 
largest stress drop, while the 1994 Reading earthquake has the smallest. The Saguenay earthquake was the deepest large earthquake while the Reading earthquake was the shallowest.

The regression results presented in figures 23-24 and 27-30 show that stress drop behaves similarly with moment magnitude and source depth for all three event sets. For each set of earthquakes, the stress drop increases with source depth more strongly than with magnitude. This result appears adequately robust; the variation of stress drop with moment magnitude for the Eastern Quebec, Ontario, and United States event sets is $\log (\Delta \sigma) \propto(0.10,0.13,0.08) M_{\mathrm{w}}$, respectively, while the variation with source depth is $\log (\Delta \sigma) \propto(0.66,0.85,0.58) \log (h)$.

The average stress drop for the United States earthquakes is 60 percent of the average stress drop for the eastern Quebec and Ontario earthquakes. Unfortunately, the set of United States earthquakes has the fewest events and is the least compact or "regional." The difficulty of assigning these earthquakes to a single region is exacerbated by a change in source mechanism. The earthquakes in New England are thrust events, while the earthquakes in Ohio, Pennsylvania, and Michigan are strike-slip events.

Our analysis shows that the stress drop of the Saguenay earthquake is controlled by three factors; the magnitude of the earthquake, the depth of the earthquake, and the region that it occurred in. The slight increase of stress drop with magnitude that we obtain implies that an $M_{\mathrm{w}} 6.5$ earthquake that occurred at the same depth would be expected to have a 20 percent greater stress drop. The increase of stress drop with source depth implies that a similar size earthquake located at a depth of $15 \mathrm{~km}$ would be expected to have a 40 percent smaller stress drop. Finally, the difference in average stress drop between the different regions implies that if a similar size earthquake occurred in the United States, it would have a 40 percent smaller stress drop. This last inference depends explicitly on the regionalization determined in this report, and should be considered speculative.

Table 2. Source parameters of $M_{\mathrm{w}}>4$ earthquakes.

[ $M_{\mathrm{w}}$, moment magnitude; $M_{\mathrm{o}}$, seismic moment; $E_{\mathrm{s}}$, radiated energy; $\Delta \sigma$, stress drop; FS, foreshock]

\begin{tabular}{lcccccc}
\hline \multicolumn{1}{c}{$\begin{array}{c}\text { Event, } \\
\text { Province }\end{array}$} & Date & $\begin{array}{c}\text { Depth } \\
\text { in kilometers }\end{array}$ & $M_{\mathrm{w}}$ & $\begin{array}{c}M_{\mathbf{o}} \\
\text { in dyne-cm }\end{array}$ & $\begin{array}{c}E_{\mathbf{s}} \\
\text { in dyne-cm }\end{array}$ & $\begin{array}{c}\Delta \sigma \\
\text { in bars }\end{array}$ \\
\hline Saguenay FS, QC & $11 / 23 / 88$ & 29 & 4.20 & $2.5 \mathrm{E}+22$ & $4.84 \mathrm{E}+18$ & 146 \\
Saguenay, QC & $11 / 25 / 88$ & 29 & 5.78 & $5.8 \mathrm{E}+24$ & $5.42 \mathrm{E}+20$ & 644 \\
Payne Bay, QC & $3 / 16 / 89$ & 18 & 5.03 & $4.4 \mathrm{E}+23$ & $4.99 \mathrm{E}+19$ & 236 \\
Ungava, QC & $12 / 25 / 89$ & 3 & 6.05 & $1.5 \mathrm{E}+25$ & $9.73 \mathrm{E}+19$ & 105 \\
\hline Ungava FS, QC & $12 / 25 / 89$ & 3 & 4.71 & $1.5 \mathrm{E}+23$ & $9.00 \mathrm{E}+18$ & 180 \\
Mt Laurier, QC & $10 / 19 / 90$ & 12 & 4.42 & $5.4 \mathrm{E}+22$ & $3.13 \mathrm{E}+18$ & 162 \\
\hline Reading, PA & $1 / 16 / 94$ & 2 & 4.59 & $9.7 \mathrm{E}+22$ & $7.17 \mathrm{E}+16$ & 4.5 \\
Roes Strait, NU & $9 / 5 / 94$ & 18 & 4.06 & $1.6 \mathrm{E}+22$ & $4.23 \mathrm{E}+18$ & 175 \\
\hline Cap-Rouge, QC & $11 / 6 / 97$ & 22 & 4.42 & $5.3 \mathrm{E}+22$ & $4.09 \mathrm{E}+18$ & 194 \\
Nunavit, NU & $12 / 6 / 97$ & 10 & 5.01 & $4.1 \mathrm{E}+23$ & $3.91 \mathrm{E}+19$ & 186 \\
\hline Pymatuning, PA & $9 / 25 / 98$ & 2 & 4.56 & $8.8 \mathrm{E}+22$ & $4.76 \mathrm{E}+18$ & 89 \\
Ste-Anne-des-Monts & $3 / 16 / 99$ & 18 & 4.36 & $4.4 \mathrm{E}+22$ & $5.39 \mathrm{E}+18$ & 337 \\
Kipawa, QC & $1 / 1 / 00$ & 13 & 4.55 & $8.5 \mathrm{E}+22$ & $3.12 \mathrm{E}+18$ & 65 \\
Ausable Forks, NY & $4 / 20 / 02$ & 11 & 4.94 & $3.3 \mathrm{E}+23$ & $2.58 \mathrm{E}+19$ & 215 \\
Southampton, NU & $8 / 26 / 04$ & 23 & 4.22 & $2.7 \mathrm{E}+22$ & $2.88 \mathrm{E}+18$ & 162 \\
Rivière-du-Loup, QC & $3 / 6 / 05$ & 15 & 4.62 & $1.1 \mathrm{E}+23$ & $1.29 \mathrm{E}+19$ & 211 \\
\hline Val-des-Bois, QC & $6 / 23 / 10$ & 22 & 5.06 & $4.9 \mathrm{E}+23$ & $4.15 \mathrm{E}+19$ & 146 \\
\hline Mineral, VA & $8 / 23 / 11$ & 7 & 5.72 & $4.8 \mathrm{E}+24$ & $1.95 \mathrm{E}+19$ & 233 \\
\hline Waterboro, ME & $10 / 16 / 12$ & 7 & 4.09 & $1.7 \mathrm{E}+22$ & $3.18 \mathrm{E}+18$ & 183 \\
Shawville, ON & $5 / 17 / 13$ & 12 & 4.49 & $6.9 \mathrm{E}+22$ & $3.19 \mathrm{E}+18$ & 95 \\
\hline Galesburg, MI & $5 / 2 / 15$ & 6 & 4.39 & $4.9 \mathrm{E}+22$ & $1.62 \mathrm{E}+18$ & 94 \\
\hline
\end{tabular}




\section{References Cited}

Adams, J., Wetmiller, R.J., Hasegawa, H.S., and Drysdale, J., 1991, The first surface faulting from a historical intraplate earthquake in North America: Nature, v. 352, p. 617-619, https://doi.org/10.1038/352617a0.

Aki, K., and Chouet, B., 1975, Origin of coda waves-Source, attenuation, and scattering effects: Journal of Geophysical Research, v. 80, no. 23, p. 3,322-3,342, https://doi.org/10.1029/JB080i023p03322.

Anderson, J.G., and Hough, S.E., 1984, A model for the shape of the fourier amplitude spectrum of acceleration at high frequencies: Bulletin of the Seismological Society of America, v. 74, no. 5, p. 1,969-1,993.

Andrews, D.J. 1986, Objective determination of source parameters and similarity of earthquakes of different size, in Das, S., Boatwright, J., and Scholz, C.H., eds., Earthquake Source Mechanics: Washington, D.C., American Geophysical Union, p. 259-268.

Atkinson, G.M., and Boore, D.M., 1995, Ground-motion relations for eastern North America: Bulletin of the Seismological Society of America, v. 85, no. 1, p. 17-30.

Atkinson, G.M., and Boore, D.M., 2014, The attenuation of Fourier amplitudes for rock sites in eastern North America: Bulletin of the Seismological Society of America, v. 104, no. 1, p. 513-528.

Atkinson, G.M., and Mereu, R.F., 1992, The shape of ground motion attenuation curves in southeastern Canada: Bulletin of the Seismological Society of America, v. 82, no. 5, p. 2,0142,021 .

Bent, A.L., 1994, The $1989\left(M_{s}\right.$ 6.3) Ungava, Quebec, earthquake-A complex intraplate event: Bulletin of the Seismological Society of America, v. 84, no. 4, p. 1,075-1,088.

Benz, H.M., Frankel, A., and Boore, D.M., 1997, Regional $\mathrm{Lg}$ attenuation for the continental United States: Bulletin of the Seismological Society of America, v. 87, no. 3, p. 606-619.

Boatwright, J., and Choy, G.L., 1992, Acceleration source spectra anticipated for large earthquakes in northeastern North America: Bulletin of the Seismological Society of America, v. 82, no. 2, p. 660-682.

Boatwright, J., and Seekins, L., 2011, Regional spectral analysis of three moderate earthquakes in northeastern North America: Bulletin of the Seismological Society of America, v. 101, no. 4, p. 1,769-1,782, https://doi.org/10.1785/gssrl.83.1.190.

Boore, D.M., 2012, Updated determination of stress parameters for several well-recorded earthquakes in eastern North America: Seismological Research Letters, v. 83, no. 1, p. 190199.

Boore, D.M., and Atkinson, G.M., 1992, Source spectra for the 1988 Saguenay, Quebec, earthquakes: Bulletin of the Seismological Society of America, v. 82, no. 2, p. 683-719.

Boore, D.M., Campbell, K.W., and Atkinson, G.M., 2010, Determination of stress parameters for eight well-recorded earthquakes in eastern North America: Bulletin of the Seismological Society of America, v. 100, no. 4, p. 1,632-1,645, https://doi.org/10.1785/0120090328.

Boore, D.M., and Joyner, W.B., 1997, Site amplifications for generic rock sites: Bulletin of the Seismological Society of America, v. 87, no. 2, p. 327-341.

Brune, J.N., 1970, Tectonic stress and the spectra of seismic shear waves from earthquakes: Journal of Geophysical Research, v. 75, no. 26, p. 4,997-5,009, https://doi.org/10.1029/JB075i026p04997. 
Du, W., Kim, W.-Y., and Sykes, L.R., 2003, Earthquake source parameters and state of stress for the northeastern United States and southeastern Canada from analysis of regional seismograms: Bulletin of the Seismological Society of America, v. 93, no. 4, p. 1,633-1,648, https://doi.org/10.1785/0120020217.

Erickson, D., McNamara, D.E., and Benz, H.M., 2004, Frequency-dependent $L g Q$ within the continental United States: Bulletin of the Seismological Society of America, v. 94, no. 5, p. 1,630-1,643, https://doi.org/10.1785/012003218.

Johnston, A.C., 1996, Seismic moment assessment of earthquakes in stable continental regionsIII. New Madrid 1811-1812, Charleston 1886 and Lisbon 1755: Geophysical Journal International, v. 126, no. 2, p. 314-344, https://doi.org/10.1111/j.1365-246X.1996.tb05294.x.

Pasyanos, M.E., 2013, A lithospheric attenuation model of North America: Bulletin of the Seismological Society of America, v. 103, no. 6, p. 3,321-3,333, https://doi.org/10.1785/0120130122.

Shin, T.-C., and Hermann, R.G., 1987, Lg attenuation and source studies using 1982 Miramichi data: Bulletin of the Seismological Society of America, v. 77, no. 2, p. 384-397.

Somerville, P.G., McLaren, J.P., Saikia, C.K., and Helmberger, D.V., 1990, The 25 November 1988 Saguenay, Quebec, earthquake-Source parameters and the attenuation of strong ground motion: Bulletin of the Seismological Society of America, v. 80, no. 5, p. 1,118-1,143.

Street, R.L., Herrmann, R.B., and Nuttli, O.W., 1975, Spectral characteristics of the $L g$ wave generated by central United States earthquakes: Geophysical Journal International, v. 41, no. 1, p. 51-63, https://doi.org/10.1111/j.1365-246X.1975.tb05484.x.

Woodgold, C.R.D., 1990, Estimation of $Q$ in eastern Canada using coda waves: Bulletin of the Seismological Society of America, v. 80, no. 2, p. 411-429. 